\title{
Why Is Collaborative Agglomeration of Innovation so Important for Improving Regional Innovation Capabilities? A Perspective Based on Collaborative Agglomeration of Industry-University-Research Institution
}

\author{
Jing Li $\mathbb{D}$ and Jialong Xing \\ Business School, Nanjing Normal University, Nanjing 210023, China \\ Correspondence should be addressed to Jing Li; lijing_hp@126.com
}

Received 6 July 2020; Revised 15 September 2020; Accepted 16 September 2020; Published 30 September 2020

Academic Editor: Dimitri Volchenkov

Copyright (c) 2020 Jing Li and Jialong Xing. This is an open access article distributed under the Creative Commons Attribution License, which permits unrestricted use, distribution, and reproduction in any medium, provided the original work is properly cited.

\begin{abstract}
Exploring the impact of collaborative agglomeration of industry-university-research institution innovation on regional innovation capabilities is of great significance for promoting China's high-quality economic development. This paper introduces the level of innovation collaborative agglomeration into the $\mathrm{C}-\mathrm{H}$ production density model to theoretically explain the mechanism of the influence of innovation collaborative agglomeration on regional innovation capacity. On this basis, using the 2011-2017 Chinese subprovincial panel data to measure the level of regional innovation collaborative agglomeration and establishing a spatial model, the impact of innovation collaborative agglomeration on regional innovation capacity is empirically examined in two stages: knowledge innovation and outcome transformation. The study finds that the innovation collaborative agglomeration and the regional innovation capacity present a typical inverted U-shape relationship, while the human capital and the regional innovation capacity present an inverted $\mathrm{N}$-shape relationship in the stage of knowledge innovation. There is a U-shaped relationship between the innovation collaborative agglomeration and the regional innovation capacity in the outcome transformation stage, while the impact of human capital on regional innovation capacity is not obvious. This result is still robust after replacing the core explanatory variables and the spatial weight matrix. In terms of three regions, the innovation collaborative agglomeration and the human capital in the middle and eastern regions have a stronger impact on regional innovation capacity than in the western region. The findings of this paper provide policy insights for the innovation collaborative agglomeration of industry, university, and research institution to promote regional innovation capacity.
\end{abstract}

\section{Introduction}

With the slowdown of China's economic growth, the path of high-quality development with innovation as the core becomes an inevitable choice for the future development of the Chinese economy [1,2]. Since Etzkowitz [3] proposed that University-Industry Collaboration (UIC) is the "third mission" of the university, University-Industry-Research Institution (URI) collaborative innovation has received increasing attention from scholars. According to the collaboration theory, a URI collaborative innovation system is a composite system consisting of three subsystems: industries, universities, and independent research institutions, and URI collaborative innovation can reduce the cost of innovation entities, thus helping to increase the likelihood of successful innovation [4]. However, the overall effectiveness of the current Chinese innovation system is still inadequate, and the shortcomings of the independent innovation capacity are prominent [5]. The uneven spatial distribution of regional innovation capacity and the lack of effective collaboration among industries, universities, and research institutions within the regional innovation system [6] have become important issues constraining the high-quality development of China's economy. Therefore, how to further enhance the 
collaborative agglomeration level of the URI innovation sectors and improve regional innovation capacity has become an important practical issue to be faced in the process of implementing China's innovation-driven development strategy and building an innovative country.

In the high speed of economic growth in the past, the improvement of regional innovation capacity mainly relied on the scale expansion and concentration of innovation factors. Although the positive effects of agglomeration on economic growth and industrial development are well validated by existing studies [7-9], a constant expansion of scale is not necessarily always beneficial to economic development. It also causes undesirable consequences such as congestion, environmental pollution, and mismatch between the scale of innovation clusters and regional innovation capacity [10-15]. Under such circumstances, we should pay attention not only to the scale of innovation agglomeration but also the structure of the innovation subjects in the agglomeration area so that the IUR innovation subjects can effectively cooperate and jointly promote the improvement of regional innovation capacity. The collaborative innovation of IUR in the agglomeration area relying on the innovation system is not only conducive to exerting their respective innovation advantages [16] and promoting the overall improvement of regional innovation capacity $[17,18]$ but also conducive to each subject learning from each other in the process of collaboration, thus promoting the improvement of their innovation capacity [19]. However, focusing only on the scale of innovation agglomeration and neglecting the structural optimization and collaboration among the various entities of IUR within the agglomeration area will lead to a disconnect between knowledge innovation and outcome transformation, thus adversely affecting the improvement of regional innovation capacity [20].

The collaborative agglomeration theory provides a theoretical basis for this paper to investigate the problem of innovation collaborative agglomeration of IUR from the composite perspective of agglomeration and collaboration. Innovation collaborative agglomeration of IUR has the dual attributes of agglomeration and collaboration. On the one hand, the innovation agglomeration in the IUR sector helps to promote the formation of innovative industrial value chains and bring cost advantages to members of the innovation system, economies of scale, and city brand advantages [21]. On the other hand, collaborative innovation of IUR facilitates the full use of heterogeneous knowledge and reduces the cost of innovation [19]. Therefore, innovation collaborative agglomeration can be understood as a process in which all innovation entities (mainly the IUR sectors) in the innovation agglomeration zone work together to promote regional innovation capacity through complementary advantages and collaborative cooperation. Compared with the concepts of agglomeration or collaboration, innovation collaborative agglomeration has the connotation of both agglomeration and collaboration, which helps to grasp more comprehensively the interrelationship among IUR departments within the agglomeration and thus provides a reference for relevant government departments to optimize the regional innovation structure and promote the scientific formulation of policies related to the enhancement of regional innovation capacity.

In the existing literatures, some scholars have already examined the impact of industrial collaborative agglomeration on industrial development and economic growth [22-28]. Although the existing literature has carried out some meaningful discussions on the problem of interindustry collaborative agglomeration, the abovementioned studies mainly focus on the impact of manufacturing and production service collaborative agglomeration on industrial innovation capacity and industrial development. As for the issue of URI innovation collaborative agglomeration affecting regional innovation capacity, which is the concern of this paper, existing research studies have not been analyzed. The industry-university-research institution, as an important part of the regional innovation system, relies on its knowledge advantage to differentiate into innovation activities, thus can enhance the technological effects of innovation [19]. Therefore, taking the issue of URI innovation collaborative agglomeration as an object of study, we can more comprehensively examine the impact of URI innovation collaborative agglomeration on regional innovation capacity, which is of great practical significance for improving regional innovation capacity [6]. Currently, methods to measure the level of interindustry collaborative agglomeration include the E-G index [29], D-O index [30], Colocalization index [31], $\gamma$ index [32], and $\Theta$ index [33]. The E-G index mainly measures the level of industry concentration at the national level, while the $\mathrm{D}-\mathrm{O}$ index and Colocalization index require accurate data on the location of manufacturers, which are not commonly used in China. The $\gamma$ index and $\Theta$ index are methods improved on the E-G index, which can more comprehensively reflect the level of collaborative agglomeration among industries. However, the above measurement methods are limited to the research on the level of collaborative agglomeration between two industries and cannot be used directly to measure the level of collaborative agglomeration among IUR sectors. The entropy value method can comprehensively measure the innovation collaborative agglomeration level of IUR based on measuring the level of any two sectors of IUR separately $[34,35]$, and the indicator weights are objective and credible under this method.

In summary, the established literature has examined the impact of industry-university-research institution innovation clustering $[16,21]$ and collaborative innovation $[18,19]$ on regional economic growth, respectively, and some scholars have also discussed the issue of synergistic clustering between the two industries [24-28]. However, there is less studies on the innovation collaborative agglomeration of IUR affecting regional innovation capacity. In this study, we empirically investigate the impact of IUR innovation collaborative agglomeration on regional innovation capacity based on a comprehensive measurement of the innovation collaborative agglomeration level. Compared with previous studies, the main contributions of this paper are as follows. (1) According to the theory of collaborative agglomeration, this paper studies the collaborative agglomeration of the 
three departments of industry, university, and research institution and mathematically derives the mechanism of innovation collaborative agglomeration on regional innovation capacity. (2) Based on considering both the scale and the quality of collaborative agglomeration, the entropy method is used to measure the level of IUR regional innovation collaborative agglomeration to achieve the objective observation. (3) Under the framework of New Economic Geography, a spatial weight matrix is introduced to explore the spatial correlation between innovation collaborative agglomeration and regional innovation capacity, and a spatial econometric model is established to empirically analyze the impact of innovation collaborative agglomeration on regional innovation capacity.

The paper is organized as follows. Section 2 presents the theoretical model and hypotheses; Section 3 shows the measuring method and results of innovation collaborative agglomeration; Section 4 explains the model and variables; Section 5 analyzes and discusses the empirical results; Section 6 conducts the robustness test, and Section 7 draws the research conclusion and makes policy recommendations.

\section{Theoretical Model and Hypotheses}

Economic agglomeration can bring spillover effects through sharing, matching, and learning. Ciccone and Hall [36] have proposed the $\mathrm{C}-\mathrm{H}$ production density model for exploring agglomeration externalities due to the density of economic activity. The model assumes that the spatial distribution of production factors is homogeneous, and output density is determined by total output, total area, and inputs per unit area. There are incremental returns to scale. The basic form of the $\mathrm{C}-\mathrm{H}$ model under the above assumptions is as follows:

$$
q_{i}=\frac{Q_{i}}{A_{i}}=\Omega_{i}\left(n_{i}^{\beta} k_{i}^{1-\beta}\right)^{\alpha}\left(\frac{Q_{i}}{A_{i}}\right)^{(\lambda-1) / \lambda},
$$

where $Q_{i}$ and $A_{i}$ are the levels of regional innovation output and regional size, respectively, $q_{i}$ denotes the innovation output per unit size of the $i$ th region (i.e., the density of innovation output), reflecting the agglomeration level of the innovation economy, $\Omega_{i}$ is the Hicks-neutral parameter, $n_{i}$ is the employment density (i.e., the number of persons employed per unit size: $\left.N_{i} / A_{i}\right), k_{i}$ is capital density (i.e., capital input per unit size: $\left.K_{i} / A_{i}\right), \alpha(0<\alpha<1)$ is the coefficient of return to labor and capital, which represents the crowding effect of innovation collaborative agglomeration, $\beta(0<\beta \leq 1)$ is the share of labor input, $\lambda$ is the parameter of output density, and $\lambda>1$, indicating the positive externalities of innovation collaborative agglomeration.

Innovation output depends not only on the input density of regional innovation factors (human capital, physical capital, etc.) but also on the level of collaboration among various innovation sectors, such as industry, university, and research institution. Agglomeration without coordination will bring crowding effect and result in uneconomical agglomeration. Therefore, based on the basic framework of the $\mathrm{C}-\mathrm{H}$ model, we introduce the level of innovation collaborative agglomeration $\Theta$ to the $\mathrm{C}-\mathrm{H}$ model and investigate the influence of IUR innovation collaborative agglomeration on regional innovation capacity from the aspects of innovation factor input density and the collaborative innovation.

After the introduction the level of innovation collaborative agglomeration $\Theta$, equation (1) is rewritten as follows:

$$
q_{i}=\frac{Q_{i}}{A_{i}}=\Omega_{i}\left(n_{i}^{\beta} k_{i}^{1-\beta}\right)^{\alpha}\left(\Theta^{\gamma} \frac{Q_{i}}{A_{i}}\right)^{(\lambda-1) / \lambda},
$$

where $\gamma$ is the coefficient $(\gamma>0)$. Take the logarithm of both sides of equation (2) simultaneously, and then derive for $k_{i}$ :

$$
\frac{\partial q_{i}}{\partial k_{i}}=\frac{\alpha(1-\beta)}{k_{i}} q_{i} .
$$

Assume that the capital can move perfectly across regions so that, in equilibrium capital price, $r$ is equal across regions. The marginal output of capital will be equal to capital price when the factor market reaches equilibrium. So, let $\partial q_{i} / \partial k_{i}=r$; then, we get the demand density of capital $k_{i}$ :

$$
k_{i}=\frac{K_{i}}{A_{i}}=\frac{\alpha(1-\beta)}{r} \frac{Q_{i}}{A_{i}} .
$$

Substitute equation (4) into equation (2) to organize the equation on innovation capacity:

$$
\begin{aligned}
\frac{Q_{i}}{N_{i}}= & \Omega_{i}^{\lambda /(1-\alpha(1-\beta) \lambda)}\left[\frac{\alpha(1-\beta)}{r}\right]^{\alpha(1-\beta) \lambda /(1-\alpha(1-\beta) \lambda)} \\
& \cdot n_{i}^{(\alpha \lambda-1) /(1-\alpha(1-\beta) \lambda)} \Theta_{i}^{\gamma(\lambda-1) /(1-\alpha(1-\beta) \lambda)} .
\end{aligned}
$$

By taking the logarithm of both sides simultaneously, equation (5) can be rewritten as follows:

$$
\begin{aligned}
\ln \frac{Q_{i}}{N_{i}}= & \frac{\lambda}{1-\alpha(1-\beta) \lambda} \ln \Omega_{i}+\frac{\alpha(1-\beta)}{1-\alpha(1-\beta) \lambda} \ln \frac{\alpha(1-\beta) \lambda}{r} \\
& +\frac{\alpha \lambda-1}{1-\alpha(1-\beta) \lambda} \ln n_{i}+\frac{\gamma(\lambda-1)}{1-\alpha(1-\beta) \lambda} \ln \Theta_{i},
\end{aligned}
$$

where $\ln \left(Q_{i} / N_{i}\right)$ stands for regional innovation capacity, $\ln \Theta_{i}$ stands for innovation collaborative agglomeration level, and $\ln n_{i}$ stands for human capital level. The impact of innovation collaborative agglomeration on regional innovation capacity depends on the sign of its coefficient $\gamma(\lambda-1) /(1-\alpha(1-\beta) \lambda)$, positive or negative. So, does the level of human capital. Figure 1 displays the impact illustration of the innovation collaborative agglomeration and human capital level on regional innovation capacity. The practical implications of the positive or negative coefficient are discussed in detail below.

\subsection{Impact of Innovation Collaborative Agglomeration on} Regional Innovation Capacity. When $1<\lambda<(1 / \alpha(1-\beta))$, the coefficient sign is positive, and innovation collaborative agglomeration promotes regional innovation capacity. At this stage, innovation collaborative agglomeration promotes 


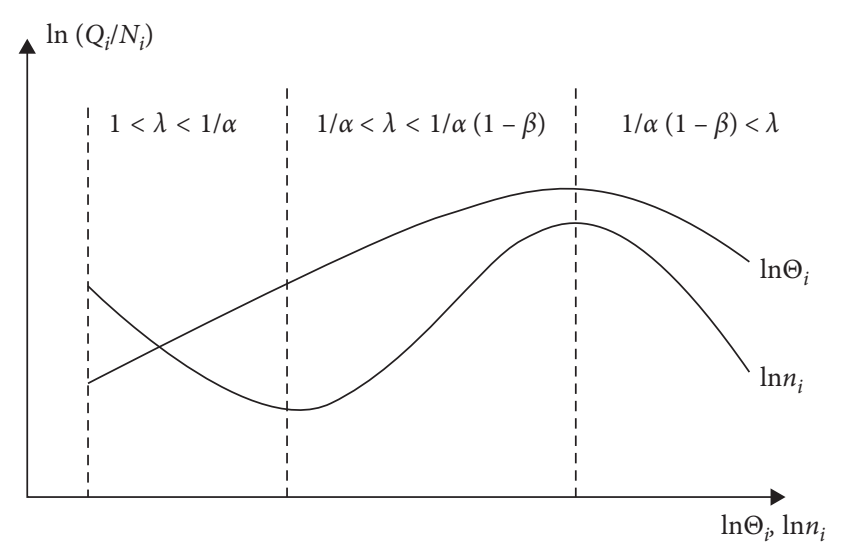

Figure 1: Static analysis diagram of $\ln \Theta_{i}, \ln n_{i}$ affecting $\ln \left(Q_{i} / N_{i}\right)$.

the transfer and sharing of knowledge and information, which makes the potential innovation cost decrease. Knowledge innovation achievements can be quickly transformed into products through the production platform provided by the enterprise; then, the innovation collaborative agglomeration level can be improved since the feedback and encouragement from the revenue of products. The positive role of innovation collaborative agglomeration in enhancing regional innovation capacity has been continuously strengthened.

When $(1 / \alpha(1-\beta))<\lambda$, the coefficient sign is negative, and innovation collaborative agglomeration inhibits the improvement of regional innovation capacity. Excessive innovation collaborative agglomeration will eventually cause crowding effects such as lowering the efficiency of IUR collaboration and the relative inadequate supply of innovation infrastructure, and when the promotion effect of innovation collaborative agglomeration on regional innovation capacity is weaker than the crowding effect, the further improvement of the innovation collaborative agglomeration level is not conducive to the improvement of regional innovation capacity.

Based on the above analysis, hypothesis $\mathrm{H} 1$ is proposed: ceteris paribus, and there is an inverted U-shaped relationship between innovation collaborative agglomeration and regional innovation capacity.

2.2. Impact of the Human Capital Level on Regional Innovation Capacity. When $1<\lambda<(1 / \alpha)$, the coefficient sign is negative, and the increase in the level of human capital is detrimental to the innovative ability of the region. At the initial stage of the innovation economy, a favorable environment for innovation collaboration and agglomeration has not yet been formed. Innovation networks and platforms also have not yet been established. For these reasons, the mismatch between human capital and physical capital has led to high input and low output of innovation activities. Besides, there is a certain time lag effect from the input to the output of human capital. Both of these two reasons have led to a decline in regional innovation capacity while human capital is being upgraded.
When $(1 / \alpha)<\lambda<(1 / \alpha(1-\beta))$, the coefficient sign is positive and the increase in the level of human capital contributes to the increase in regional innovation capacity. At this stage, a collaborative innovation network has been initially formed in the region, creating a positive and open innovation environment, which can be attractive to innovative talents. Increased level of human capital drives regional innovation capacity by facilitating the accumulation and diffusion of knowledge and technology, which, in turn, strengthens regional collaborative innovation networks. The formation of a circular cumulative causal chain between the human capital level and the region's innovation capacity is a distinctive feature of this phase.

When $(1 / \alpha(1-\beta))<\lambda$, the coefficient sign is negative, and the increase in the level of human capital is not conducive to the improvement of regional innovation capacity. An overconcentration of innovative talents will increasingly complicate regional innovation networks, and crowding effects such as resource constraints, traffic congestion, and environmental pollution will offset or even overshadow the innovation effects. As a result, regional innovation capacity decreases while the level of human capital increase during this period.

Based on the above analysis, hypothesis $\mathrm{H} 2$ is proposed: ceteris paribus, and there is an inverted $\mathrm{N}$-shaped relationship between the level of human capital and regional innovation capacity.

The above analysis shows that there is a nonlinear effect of innovation collaborative agglomeration and human capital level on regional innovation capacity. It is worth noting that the level of innovation collaborative agglomeration, the level of human capital, and regional innovation capacity are all affected by the spatial structure. Zhang and Li [37] empirically found that provincial regional innovation output shows spatial dependence. Li et al. [38] confirmed that there is a significant positive spatial correlation of regional innovation in China. Yu and Liu [39] pointed out that the innovation capacity of different regions has an obvious spatial correlation. Bai and Jiang [40] empirically examined the impact of collaborative innovation and spatial association on regional innovation performance, and they found that collaborative innovation can promote the improvement of regional innovation performance. These research studies show that there is a spatial correlation between regional innovation capacity. Consider that regional innovation capacity is affected by innovation collaborative agglomeration. Therefore, there may also be a spatial correlation between innovation collaborative agglomeration and regional innovation capacity. Based on this, the following hypothesis is proposed.

Hypothesis H3: there is a spatial correlation between innovation collaborative agglomeration and regional innovation capacity.

\section{Measurement of Innovation Collaborative Agglomeration}

3.1. Method. Collaborative agglomeration of innovation refers to an agglomeration process in which industry, 
university, and research institution in the region work together to enhance regional innovation capacity through complementary advantages and collaboration. Innovation collaborative agglomeration emphasizes the connotation of both the clustering effect and the synergies of the IUR within the region. In terms of agglomeration, there is a knowledge spillover effect of innovation clustering, which helps to reduce $R \& D$ costs and increase regional innovation capacity. From the perspective of collaboration, as an important subsystem of the regional innovation system, the interaction and cooperation among the IUR sectors and among their internal innovation elements can both create an overall synergies of " $1+1+1+1>3$." Therefore, compared with the concepts of agglomeration and collaboration, the concept of innovation collaborative agglomeration can more objectively and accurately grasp the interaction of the IUR, thus helping to investigate the impact of IUR innovation collaborative agglomeration on regional innovation capacity. In the study, the $\Theta$ index [33] is firstly used to calculate the level of collaborative agglomeration of industry-university, industry-research institution, and university-research institution in a certain region, and then the entropy value method is used to obtain the innovation collaborative agglomeration of IUR. The process is as follows.

Calculate the location entropy index $\mathrm{LQ}_{i j}$ of the IUR innovation subjects of a province in the country:

$$
\mathrm{LQ}_{i j}=\frac{\left(q_{i j} / q_{j}\right)}{\left(q_{i} / q\right)},
$$

where $\mathrm{LQ}_{i j}$ is the nationwide location entropy index of $i$ innovative subject in $j$ province, $q_{i j}$ is the full time equivalent of R\&D personnel of the $i$ innovative subject in $j$ province, $q_{j}$ is the full time equivalent of R\&D personnel in industry-university, industry-research institution, and university-research institution innovative subjects in $j$ province, $q_{i}$ is the full time equivalent of the R\&D personnel of the $i$ innovative subject in whole country, $q$ is a full time equivalent of $R \& D$ personnel in industry-university, industry-research institution, and university-research institution innovative subjects in whole country. Using equation (8), we can calculate the collaborative agglomeration level of industry-university, industry-research institution, and university-research institution, respectively:

$$
\mathrm{LQ}_{\text {gat }}=\left(1-\frac{\left|\mathrm{LQ}_{m}-\mathrm{LQ}_{n}\right|}{\mathrm{LQ}_{m}+\mathrm{LQ}_{n}}\right)+\left|\mathrm{LQ}_{m}+\mathrm{LQ}_{n}\right| .
$$

$\mathrm{LQ}_{m}$ and $\mathrm{LQ}_{n}$, respectively, represent the location entropy indexes of industry and university in the industryuniversity agglomeration, or the location entropy indexes of industry and research institution in the industry-research institution agglomeration, or the location entropy indexes of university and research institution in the university-research institution agglomeration.

The first item on the right side of equation (8) represents the quality of collaborative agglomeration and the second term represents the depth of collaborative agglomeration, which reflects the level of integration and the scale of the collaborative agglomeration subjects, respectively. The larger scale of cohesion and the higher level of integration, the larger collaborative agglomeration value $\mathrm{LQ}_{\mathrm{gat}}$.

Using equation (8), the value of collaborative agglomeration of any two sectors of IUR can be obtained. The following is the entropy method to measure the innovation collaborative agglomeration of the IUR three sectors.

Indicator selection: the indicator $\mathrm{LQ}_{\theta i j}$ represents data for the $j$ th indicator for province $i$ in year $\theta$. Here, $j=$ $1,2,3, \ldots$ and the three indicators are the level of industryuniversity collaborative agglomeration, the level of industryresearch institution collaborative agglomeration, and the level of university-research institution collaborative agglomeration, respectively.

Standardization of indicators: as each indicator is a positive measure of the regional innovation collaborative agglomeration level, it is standardized using $\mathrm{LQ}_{\theta i j}^{\prime}=\mathrm{LQ}_{\theta i j} / \mathrm{LQ}_{\max }$. Here, $\mathrm{LQ}_{\max }$ is the maximum value of indicator $j$ in all provinces of the country in that year.

$$
\begin{aligned}
& \text { Proportion of indicators: } L_{\theta i j}=\mathrm{LQ}_{\theta i j}^{\prime} / \sum_{i} \mathrm{LQ}_{\theta i j}^{\prime} \\
& \text { Entropy value for indicator } j: \quad e_{j}=-(1 / k) * \\
& \sum_{i} L_{\theta i j} * \ln \left(L_{\theta i j}\right) \text {, here } k=\ln (n) \\
& \text { Information utility value of the indicator: } g_{j}=1-e_{j} \\
& \text { Weighting of indicators: } w_{j}=g_{j} / \sum_{j} g_{j} \\
& \text { Innovation collaborative agglomeration: } \mathrm{CO}_{\theta i}= \\
& \sum_{j}\left(w_{j} * \mathrm{LQ}_{\theta i j}^{\prime}\right)
\end{aligned}
$$

$\mathrm{CO}_{\theta i}$ represents regional innovation collaborative agglomeration in province $i$ in year $\theta$, which measures the level of collaborative agglomeration among IUR in the region. The index value is between 0 and 1 . Obviously, a higher value indicates a higher level of innovation collaborative agglomeration; conversely, it indicates a lower level of innovation collaborative agglomeration.

The full-time equivalent data of R\&D personnel used in the calculation of innovation collaborative agglomeration is from the official website of the National Bureau of Statistics of China.

\subsection{Analysis of Results of Innovation Collaborative} Agglomeration. The measurement results of the innovation collaborative agglomeration for 30 provinces in mainland China (Tibet is not included) from 2011 to 2017 are reported in Table 1. The results reveal the following characteristics of innovation collaborative agglomeration in different regions of China during the study period. In the eastern region, there are regions with high innovation collaborative agglomeration such as Beijing, Hainan, and Shanghai, as well as regions with low innovation collaborative agglomeration such as Zhejiang, Guangdong, Fujian, and Jiangsu. The innovation collaborative agglomeration level in the middle and western regions is generally higher than that in the eastern regions, such as the western regions of Xinjiang, Shaanxi, and Yunnan, and the middle regions of Jilin, Heilongjiang, and Hubei, which all have a high level of IUR innovation collaborative agglomeration. The possible reason is that innovation collaborative agglomeration contains two components, namely, the quality and the scale of innovation 
TABLE 1: Results of innovation collaborative agglomeration.

\begin{tabular}{llllllll}
\hline Region & & & & Year & & & \\
& 2017 & 2016 & 2015 & 2014 & 2013 & 2012 & 2011 \\
\hline Anhui & 0.53 & 0.55 & 0.54 & 0.55 & 0.58 & 0.59 & 0.59 \\
Beijing & 0.99 & 1.00 & 1.00 & 1.00 & 1.00 & 0.99 & 0.96 \\
Fujian & 0.44 & 0.43 & 0.43 & 0.40 & 0.41 & 0.41 & 0.41 \\
Gansu & 0.77 & 0.72 & 0.72 & 0.70 & 0.74 & 0.75 & 0.76 \\
Guangdong & 0.37 & 0.38 & 0.38 & 0.37 & 0.37 & 0.37 & 0.37 \\
Guangxi & 0.71 & 0.68 & 0.68 & 0.66 & 0.71 & 0.71 & 0.68 \\
Guizhou & 0.62 & 0.62 & 0.63 & 0.64 & 0.64 & 0.66 & 0.66 \\
Hainan & 0.86 & 0.78 & 0.68 & 0.66 & 0.71 & 0.73 & 0.80 \\
Hebei & 0.57 & 0.55 & 0.54 & 0.56 & 0.58 & 0.60 & 0.59 \\
Henan & 0.48 & 0.45 & 0.45 & 0.45 & 0.48 & 0.50 & 0.50 \\
Heilongiiang & 0.70 & 0.66 & 0.67 & 0.67 & 0.69 & 0.69 & 0.65 \\
Hubei & 0.59 & 0.59 & 0.60 & 0.61 & 0.63 & 0.64 & 0.64 \\
Hunan & 0.51 & 0.52 & 0.54 & 0.56 & 0.58 & 0.58 & 0.59 \\
Jilin & 0.74 & 0.73 & 0.73 & 0.74 & 0.75 & 0.74 & 0.78 \\
Jiangsu & 0.42 & 0.41 & 0.41 & 0.42 & 0.43 & 0.43 & 0.45 \\
Jiangxi & 0.60 & 0.60 & 0.60 & 0.62 & 0.63 & 0.65 & 0.64 \\
Liaoning & 0.67 & 0.67 & 0.66 & 0.64 & 0.66 & 0.68 & 0.67 \\
Inner Mongolia & 0.58 & 0.52 & 0.52 & 0.54 & 0.59 & 0.63 & 0.64 \\
Ningxia & 0.56 & 0.58 & 0.56 & 0.56 & 0.59 & 0.61 & 0.56 \\
Qinghai & 0.71 & 0.69 & 0.76 & 0.67 & 0.70 & 0.70 & 0.71 \\
Shandong & 0.44 & 0.44 & 0.43 & 0.45 & 0.45 & 0.45 & 0.45 \\
Shanxi & 0.61 & 0.60 & 0.60 & 0.57 & 0.63 & 0.64 & 0.63 \\
Shaanxi & 0.75 & 0.74 & 0.73 & 0.73 & 0.77 & 0.80 & 0.80 \\
Shanghai & 0.66 & 0.65 & 0.65 & 0.67 & 0.68 & 0.69 & 0.68 \\
Sichuan & 0.71 & 0.73 & 0.73 & 0.72 & 0.72 & 0.73 & 0.76 \\
Tianjin & 0.61 & 0.58 & 0.56 & 0.58 & 0.60 & 0.60 & 0.62 \\
Xinjiang & 0.78 & 0.77 & 0.76 & 0.78 & 0.80 & 0.80 & 0.74 \\
Yunnan & 0.68 & 0.72 & 0.73 & 0.77 & 0.80 & 0.77 & 0.76 \\
Zhejiang & 0.36 & 0.35 & 0.35 & 0.35 & 0.36 & 0.38 & 0.37 \\
Chongqing & 0.53 & 0.55 & 0.54 & 0.52 & 0.62 & 0.63 & 0.61 \\
\hline & & & & & & &
\end{tabular}

collaborative agglomeration. So, the mismatch between the quality and the scale may lead to smaller values in the results of the entropy value method for calculating innovation collaborative agglomeration. Some middle and western regions, such as Xinjiang, Shaanxi, Yunnan, and Jilin, have a rather limited scale of IUR, which objectively encourages the limited IUR resources to be more likely to become the key nodes of the regional innovation network, thus increasing the innovation collaborative agglomeration level. On the contrary, some eastern regions, such as Jiangsu and Zhejiang, have a larger scale of IUR and a more complex network of innovation collaboration, and the influence of IUR collaboration has been diluted, resulting in a lower concentration of innovation collaboration in these regions than in the middle and western regions.

\section{Econometric Model and Variables}

4.1. Spatial Model. According to hypothesis $\mathrm{H} 1$ and $\mathrm{H} 2$, between innovation collaborative agglomeration (CO) and regional innovation capacity (CR) and the level of human capital (HUM) and regional innovation capacity (CR) both have a nonlinear relationship. Furthermore, a quadratic relationship between $\mathrm{CO}$ and $\mathrm{CR}$ and a tertiary relationship between HUM and CR are initially founded based on the sign of their coefficients. Therefore, the initial metrological model is defined as follows:

$$
\begin{aligned}
\mathrm{CR}_{i t}= & \alpha_{1} \mathrm{CO}_{i t}+\alpha_{2} \mathrm{CO}_{i t}^{2}+\alpha_{3} \mathrm{HUM}_{i t}+\alpha_{4} \mathrm{HUM}_{i t}^{2} \\
& +\alpha_{5} \mathrm{HUM}_{i t}^{3}+\mathbf{X}_{\mathrm{it}}^{\prime} \boldsymbol{\beta}_{\mathbf{1}}+\varepsilon_{i t},
\end{aligned}
$$

where the subscripts $i$ and $t$ represent region and year, respectively, $\mathbf{X}_{\mathbf{i t}}^{\prime}$ is a matrix of control variables other than $\mathrm{HUM}_{i t}$, including infrastructure BASE ${ }_{i t}$, government support for innovation $\mathrm{GOV}_{i t}$, industrial structure $\mathrm{IND}_{i t}$, and openness to the outside world $\mathrm{OPE}_{i t}, \boldsymbol{\beta}_{\mathbf{1}}$ is the corresponding vector of coefficients, and $\varepsilon_{i t}$ is the error term.

Based on the spatial correlation between innovation collaborative agglomeration and regional innovation capacity proposed by hypothesis $\mathrm{H} 3$, a general form of spatially nested model [41] is built by introducing a spatial weight matrix into equation (9). The basic form of the model becomes

$$
\begin{aligned}
\mathrm{CR}_{i t} & =\rho W \mathrm{CR}_{i t}+\mathbf{Y}_{\mathrm{it}}^{\prime} \boldsymbol{\beta}_{\mathbf{2}}+\mathbf{W} \mathbf{Y}_{\mathbf{i t}}^{\prime} \boldsymbol{\delta}+u_{i}+\gamma_{t}+\varepsilon_{i t}, \\
\varepsilon_{i t} & =\lambda W \varepsilon_{i t}+v_{i t},
\end{aligned}
$$

where $\rho$ is the spatial autoregressive coefficient, $W$ is the rows standardization spatial weight matrix, $\mathbf{Y}_{\mathrm{it}}^{\prime}$ is a vector matrix of explanatory variables consisting of the core explanatory variables $\mathrm{CO}$ and $\mathrm{CO}^{2}$, and the control variables HUM, $\mathrm{HUM}^{2}, \mathrm{HUM}^{3}$, BASE, GOV, IND, and OPE, $\boldsymbol{\beta}_{2}$ is the coefficients vector of the explanatory variables, $\mathbf{W Y}_{\mathrm{it}} \boldsymbol{\delta}$ is the coefficients vector of the spatial lag term, $u_{i}$ is the individual effect, $\gamma_{t}$ is the time effect, $\varepsilon_{i t}$ is the residual, and $\lambda$ is the spatial error autocorrelation coefficient.

By examining whether $\lambda$ and $\rho$ are equal to 0 and $\boldsymbol{\delta}$ is equal to $\mathbf{0}$ in equation (10), the general spatial panel model can be transformed into several special spatial models. In spatial models, where the explanatory variables are not strictly exogenous, the residuals do not satisfy the independent homogeneous distribution assumption and the results are biased when using least squares estimation. The LM, LR, and Wald tests for spatial models are performed here with reference to the recommendations of Anselin [42] and Elhorst and Frerets [43]. The Spatial Durbin Model (SDM) with double fixed effects is more suitable for this study, as judged by the joint Wald test and LR test. Thus, the final form of the empirical model developed in this study is as follows:

$$
\mathrm{CR}_{i t}=\rho W \mathrm{CR}_{i t}+\mathbf{Y}_{\mathbf{i t}}^{\prime} \boldsymbol{\beta}_{\mathbf{2}}+\mathbf{W} \mathbf{Y}_{\mathbf{i t}}^{\prime} \boldsymbol{\delta}+\varepsilon_{i t} .
$$

The variables in equation (11) have the meanings described above.

4.2. Variables and Data. Interpreted variable: regional innovation capacity (CR). Innovation activities can be decomposed into two stages: knowledge innovation and outcome transformation [44-46]. In this paper, patent output and revenue from new product sales are used to measure innovation capacity at the knowledge innovation and outcome transformation stages, respectively. In order to be consistent with the meaning of regional innovation 
capacity $\ln \left(Q_{i} / N_{i}\right)$ in the theoretical model equation (6), regional innovation capacity at the stage of knowledge innovation and outcome transformation is measured by per capita domestic patent applications granted to $R \& D$ personnel in IUR (PA) and new product sales revenue per capita for R\&D personnel in IUR (NRP), respectively.

Core explanatory variable: innovation collaborative agglomeration (CO). Firstly, the $\Theta$ index is used to calculate the level of collaborative agglomeration of industry-university, industry-research institution, and university-research institution in a region, and then the entropy value method is used to calculate the level of innovation collaborative agglomeration of IUR.

Control variables: regional innovation capacity is influenced by other variables in addition to the innovation collaborative agglomeration, and the control variables listed in Table 2 are included in the spatial model with reference to existing literature.

Human capital (HUM): human capital is the stock synthesis of the various production knowledge, labor and management skills, and health qualities embedded in workers [47]. The higher the human capital level, the greater the ability of workers to acquire and apply new knowledge and technology and the greater their ability to engage in innovative activities [48]. At the same time, a high level of human capital helps deepen the division of labor and improve production efficiency [49]. The human capital level is measured here as the proportion of population with postsecondary education or higher to regional population [50].

Infrastructure (BASE): regional infrastructures, as important vehicles for regional innovation activities, are becoming increasingly important in influencing regional innovation capacity. Generally, the better the infrastructure, the better the innovation environment and the more conducive it is to attracting innovative talent and improving innovation capacity [48]. The impact of information infrastructure in the information age is becoming more and more important, and the share of total postal services in regional GDP is a good measure of the regional information infrastructure development, so this indicator is used here to measure the level of regional infrastructure.

Government support for innovation (GOV): government behavior reflects the government's attitude toward innovation, and the government can effectively compensate for market failures by guiding innovative firms [51]. Of course, excessive government intervention in the innovation economy may also distort the market mechanism and reduce the status of the main enterprise [48]. To validate the impact of government support behavior on regional innovation capacity, the share of local fiscal expenditure on science and technology as a percentage of general local budget expenditure is used as a measure of the strength of government support for innovation.

Industrial structure (IND): the industrial structure depicts the market type of the region, and the market type is closely related to the regional innovation capacity. The more developed the secondary and tertiary industries are, the higher the demand for regional innovation capacity exists. Therefore, the regional industrial structure is measured by the share of value added of secondary and tertiary industries in regional GDP.

Openness to the outside world (OPE): the increase in the level of external openness helps the flow of production factors and the rational allocation of resources [48]. By openness, firms can be exposed to the world's cutting-edge science and technology through participation in international trade, while the inflow of foreign investment can also reduce the $\mathrm{R} \& \mathrm{D}$ and learning costs of technology adoption [49]. The level of openness to the outside world is measured by the proportion of foreign direct investment (FDI) to GDP. The amount of foreign direct investment is discounted by the average price of the exchange rate of the RMB over the past years.

Due to the change in statistical standards for industrial enterprises above designated size in 2011 and missing data for some years in the Tibet Autonomous Region, panel data from 30 provinces in mainland China (excluding the Tibet Autonomous Region) from 2011 to 2017 are selected as raw data for analysis in the study. All data are from the official website of the National Statistics Office of China.

Tables 3 and 4 give the results of the descriptive statistics of the raw data and the correlation coefficients between the variables.

4.3. Spatial Weight Matrix. The geographic adjacency criterion matrix is a more commonly used spatial weight matrix, but this matrix is too simple to truely reflect spatial correlations. For example, Hebei is in close proximity to both Inner Mongolia and Beijing, but the impact of Inner Mongolia and Beijing on Hebei's economic development cannot be exactly the same [52]. The impact of two geographically contiguous regions on each other may not be equal depending on their level of economic development. In general, regions with higher levels of economic development will have a greater impact on regions with lower levels, for example, the intensity of Beijing's economic impact on Hebei will be greater than the intensity of Hebei's impact on Beijing [38]. Based on this, this paper incorporates both geographic adjacency and the level of regional economic development into the spatial weighting, where regional economic development is measured by GDP per capita data. The spatial weight matrix takes the following form:

$$
W_{2}=W_{1} * \operatorname{diag}\left(\frac{\bar{G}_{1}}{\bar{G}}, \frac{\bar{G}_{2}}{\bar{G}}, \ldots, \frac{\bar{G}_{n}}{\bar{G}}\right),
$$

where $W_{1}$ is the spatial adjacency weight matrix, $\bar{G}_{i}$ is the average of GDP per capita in a region during the period under study, and $\bar{G}$ is the average value of the national GDP per capita during the study period. The final spatial weight matrix $W$ is obtained by processing the $W_{2}$ matrix rows standardization.

\section{Results and Discussion}

5.1. Spatial Correlation of $C O$ and $C R$. In order to explain the spatial influence between innovation collaborative agglomeration and regional innovation capacity, we introduce 
TABLE 2: Qualitative description of variables.

\begin{tabular}{|c|c|c|c|c|}
\hline Variable name & Notation & Unit & Connotation & Calculation method \\
\hline \multirow{2}{*}{$\begin{array}{l}\text { Interpreted } \\
\text { variable }\end{array}$} & PA & $\begin{array}{l}\text { Piece/ } \\
\text { person }\end{array}$ & $\begin{array}{l}\text { Regional innovation capacity at the } \\
\text { knowledge innovation stage }\end{array}$ & $\begin{array}{l}\text { Per capita domestic patent applications granted to R\&D } \\
\text { personnel in IUR }\end{array}$ \\
\hline & RNP & $\begin{array}{l}10 \text { million/ } \\
\text { person }\end{array}$ & $\begin{array}{l}\text { Regional innovation capacity at the } \\
\text { outcome transformation stage }\end{array}$ & $\begin{array}{c}\text { New product sales revenue per capita for R\&D } \\
\text { personnel in IUR }\end{array}$ \\
\hline $\begin{array}{l}\text { Core explanatory } \\
\text { variables }\end{array}$ & $\mathrm{CO}$ & - & $\begin{array}{l}\text { Innovation collaborative } \\
\text { agglomeration }\end{array}$ & $\begin{array}{l}\text { Entropy method to measure the level of collaborative } \\
\text { agglomeration between any two sectors of IUR }\end{array}$ \\
\hline \multirow{5}{*}{ Control variables } & HUM & $\%$ & Human capital & $\begin{array}{c}\text { Proportion of population with postsecondary education } \\
\text { or higher to regional population }\end{array}$ \\
\hline & BASE & Ratio & Infrastructure & $\begin{array}{c}\text { Share of total post- and telecommunications services in } \\
\text { the gross regional product }\end{array}$ \\
\hline & GOV & Ratio & $\begin{array}{l}\text { Government support for } \\
\text { innovation }\end{array}$ & $\begin{array}{l}\text { Local fiscal expenditure on science and technology as a } \\
\text { proportion of general local fiscal budget expenditure }\end{array}$ \\
\hline & IND & Ratio & Industrial structure & $\begin{array}{c}\text { Value added of secondary and tertiary industries as a } \\
\text { proportion of regional GDP }\end{array}$ \\
\hline & OPE & Ratio & Openness to the outside world & Foreign direct investment as a share of regional GDP \\
\hline
\end{tabular}

TABle 3: Statistical description of each variable.

\begin{tabular}{lccccc}
\hline Variable & Sample size & Mean & Standard deviation & Minimal value & Maximum value \\
\hline PA & 210 & 0.20 & 0.09 & 0.05 & 0.01 \\
RNP & 210 & 0.22 & 0.11 & 0.35 & 0.46 \\
CO & 210 & 0.62 & 0.14 & 5.37 & 1.00 \\
HUM & 210 & 13.20 & 6.98 & 0.01 & 0.01 \\
BASE & 210 & 0.03 & 0.01 & 0.01 & 0.07 \\
GOV & 210 & 0.02 & 0.01 & 0.74 & 1.00 \\
IND & 210 & 0.90 & 0.05 & 0.05 & 1.76 \\
OPE & 210 & 0.33 & & \\
\hline
\end{tabular}

TABLE 4: Correlation coefficients between variables.

\begin{tabular}{|c|c|c|c|c|c|c|c|c|}
\hline & PA & RNP & $\mathrm{CO}$ & HUM & BASE & GOV & IND & OPE \\
\hline PA & 1.00 & & & & & & & \\
\hline RNP & 0.45 & 1.00 & & & & & & \\
\hline $\mathrm{CO}$ & -0.41 & -0.57 & 1.00 & & & & & \\
\hline HUM & 0.18 & 0.08 & 0.34 & 1.00 & & & & \\
\hline BASE & 0.29 & -0.17 & 0.10 & 0.10 & 1.00 & & & \\
\hline GOV & 0.50 & 0.45 & -0.15 & 0.68 & 0.13 & 1.00 & & \\
\hline IND & 0.32 & 0.43 & -0.25 & 0.62 & -0.05 & 0.69 & 1.00 & \\
\hline OPE & 0.34 & 0.34 & -0.02 & 0.65 & 0.20 & 0.72 & 0.51 & 1.00 \\
\hline
\end{tabular}

Moran's Index to investigate the spatial correlation between them. Referring to Rusche et al. [53], rows' standardization spatial weight matrix $W$ is introduced to measure the global spatial correlation between $\mathrm{CO}$ and $\mathrm{CR}$ using bivariate global Moran's Index. Bivariate global Moran's Index is a modification of univariate global Moran's Index. The latter examines the clustering of the same variable in geographic domain, while the former examines the correlation between two variables in the geographic domain. The specific formula for bivariate global Moran's Index is as follows:

$$
\text { Global Moran's } I=\frac{\mathrm{CO}_{i}^{\prime} W \mathrm{CR}_{j}}{N},
$$

where $N$ is the number of provinces and CR and CO need to be $z$-score normalized. Bivariate global Moran's Index takes the same range of values and meaning as univariate global Moran's Index. The results of the Moran test are shown in Table 5.

Table 5 shows that the bivariate global Moran values for CO and PA and RNP are both negative during 2011-2017 and all passed the $5 \%$ level of statistically significance test. This validates the hypothesis $\mathrm{H} 3$ that there is a spatial correlation between innovation collaborative agglomeration and regional innovation capacity. The test results are significantly negative indicating that there is a significant negative spatial correlation between local innovation collaborative agglomeration and innovation capacity of neighboring regions in 2011-2017, both at the knowledge innovation stage and the outcome transformation stage. This may be since increasing local innovation collaborative 
TABLE 5: The results of bivariate global Moran test.

\begin{tabular}{ccccccc}
\hline & \multicolumn{2}{c}{ PA and CO } & & \multicolumn{3}{c}{ RNP and CO } \\
Year & Moran's $I$ & $Z$ value & $P$ value & Year & Moran's $I$ & $Z$ value \\
\hline 2017 & $-0.24^{*}$ & -1.86 & 0.07 & 2017 & $-0.39^{* * *}$ & -3.23 \\
2016 & $-0.25^{*}$ & -2.01 & 0.05 & 2016 & $-0.34^{* * *}$ & -2.84 \\
2015 & $-0.25^{*}$ & -1.96 & 0.06 & 2015 & $-0.34^{* * *}$ & -2.76 \\
2014 & $-0.27^{* *}$ & -2.17 & 0.04 & 2014 & $-0.31^{* *}$ & -2.56 \\
2013 & $-0.32^{* *}$ & -2.59 & 0.01 & 2013 & $-0.34^{* * *}$ & -2.77 \\
2012 & $-0.36^{* * *}$ & -3.02 & 0.00 & 2012 & $-0.32^{* *}$ & -2.65 \\
2011 & $-0.36^{* * *}$ & -2.98 & 0.00 & 2011 & $-0.26^{* *}$ & -0.01 \\
\hline
\end{tabular}

Note. ${ }^{*},{ }^{* *}$, and ${ }^{* * *}$ are statistically significant at the $10 \%, 5 \%$, and $1 \%$ levels, respectively.

agglomeration often implies resources are attracted from neighboring regions, especially in the face of limited innovation resources, which leads to an increase in local innovation collaborative agglomeration and a decrease in the innovation capacity of neighboring regions and obeys a negative spatial correlation. It can also be found from Table 5 that the bivariate global Moran value of innovation collaborative agglomeration and regional innovation capacity shows an opposite trend in the knowledge innovation stage and the transformation stage, that is, the absolute value of the bivariate global Moran value in the 2011-2017 knowledge innovation stage gradually decreases, while the value gradually increases in the outcome transformation stage. This result shows that, in recent years, the siphoning effect of innovation collaborative agglomeration in China has gradually weakened at the knowledge innovation stage, but has gradually increased at the outcome transformation stage. The siphoning effect, occurring during the process of collaborative agglomeration, is closely related to the lack of collaborative cooperation among regions [27]. The analysis suggests that the weakening of the siphoning effect at the knowledge innovation stage may be due to the fact that the annual increase in the scale of innovation collaborative agglomeration in China's URI departments has mitigated the inter-regional competition and thus enhanced collaboration among innovation subjects. The strengthening may be since the fact that innovative production is protected by patents, which raises the threshold for innovation outcome transformation, and thus the increase in local innovation collaborative agglomeration is increasingly detrimental to the transfer of innovation results from neighboring regions. Therefore, enhancing interregional cooperation and strengthening regional policy integration is the key to weakening the siphoning effect in the process of collaborative agglomeration of URI innovation subjects.

Using the CO in 2017 and 2011 as the abscissa and the $W * \mathrm{PA}$ and $W * \mathrm{RNP}$ for the corresponding year as the ordinate, draw the two-variable global Moran scatter plot, as shown in Figure 2. This picture intuitively depicts the spatial correlation between the local innovation collaborative agglomeration and the innovation capacity of neighboring areas.

The four quadrants of the Moran scatterplot are referred to as the $\mathrm{HH}, \mathrm{LH}, \mathrm{LL}$, and HL regions. As we can see from the Moran scatter plot, (1) at present, only a few regions ( $\mathrm{HH}$ area) such as Beijing, Shanghai, Guangxi, and Hainan, local innovation collaborative agglomeration has played a role in improving the innovation capacity of neighboring regions, while a few regions (LL area) such as Henan and Ningxia, local innovation collaborative agglomeration has a very weak impact on the innovation capacity of neighboring regions. (2) The scattered points of Fujian, Zhejiang, Guangdong, Shandong, and Jiangsu all fall into the LH area, indicating that the development of innovation-driven economy in these regions is currently in a transitional stage, and the spillover effect of local innovation collaborative agglomeration on the innovation capacity of neighboring regions is gradually increasing. (3) Some regions (HL area) such as Gansu, Qinghai, Xinjiang, and Jilin have not only failed to improve the innovation capacity of their neighbors but also significantly suppressed the improvement, indicating that there is an obvious competition among these regions and their neighbors for innovation resources. (4) On the whole, the scattered dots in the figure are roughly distributed along the upper-left corner to the lower-right corner and mainly fall into quadrant 2 and 4, which reveals that, in recent years, local innovation collaborative agglomeration has a weak or even hindering effect on the innovation capacity of neighboring regions. Therefore, in the future, the innovation collaborative agglomeration should be further improved to promote the spatial overflow of innovation and enhance the innovation capacity of regions.

The bivariate global Moran index can examine the overall spatial relationship between innovation collaborative agglomeration and regional innovation capacity, but this overall evaluation will ignore some characteristics in the local spatial scale. So, it is necessary to adopt the bivariate local Moran index to analyze the local spatial correlation. The basic formula for the bivariate local Moran index is as follows:

$$
\text { Local Moran's } I_{i}=\mathrm{CO}_{i} W_{i} \mathrm{CR}_{j} \text {, }
$$

where $W_{i}$ refers to the new matrix formed by the $i$ th row element of the original spatial weight matrix $W$, and the remaining variables have the same meaning as the variables in equation (13).

Table 6 presents the results of the bivariate local Moran value of innovation collaborative agglomeration and regional innovation capacity. As can be seen in Table 6, the results of the local Moran index are positive or negative, which suggests that the innovation collaborative agglomeration in a given region can have a facilitating or inhibiting 

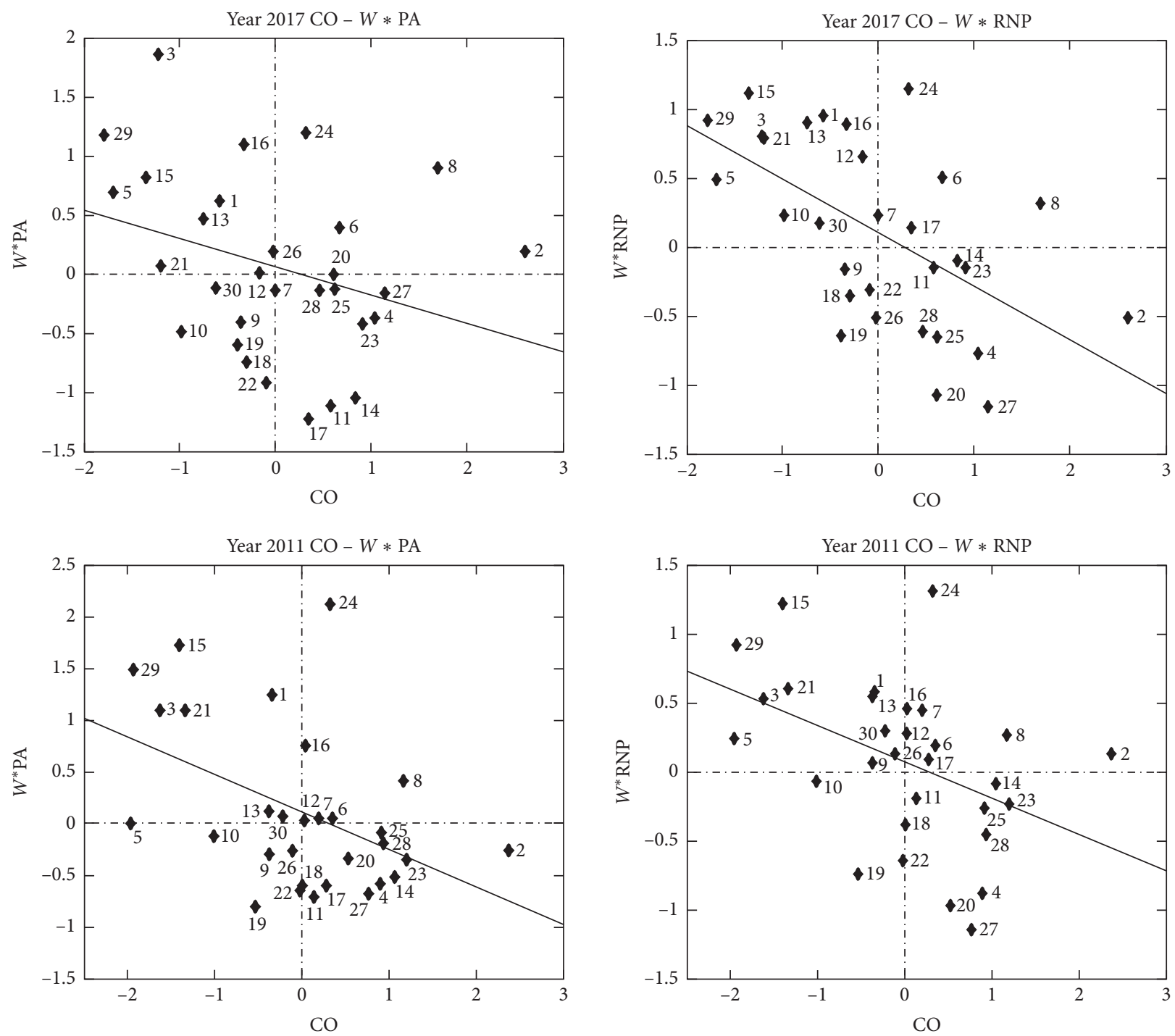

FIgURE 2: Bivariate global Moran scatterplot for 2017 and 2011 (the scatter numbers from 1 to 30 in the figure correspond to Anhui, Beijing, Fujian, Gansu, Guangdong, Guangxi, Guizhou, Hainan, Hebei, Henan, Heilongjiang, Hubei, Hunan, Jilin, Jiangsu, Jiangxi, Liaoning, Inner Mongolia, Ningxia, Qinghai, Shandong, Shanxi, Shaanxi, Shanghai, Sichuan, Tianjin, Xinjiang, Yunnan, Zhejiang, and Chongqing).

effect on the innovation capacity of its neighbors. For example, the local innovation collaborative agglomeration in Beijing, Shanghai, and Hainan promotes innovation capacity in neighboring regions, while the inhibitory effect is more pronounced in most regions such as Anhui, Guangdong, and Jilin. The local Moran values in Guizhou and Hubei are close to zero, and it can be assumed that there is no spatial correlation between innovation collaborative agglomeration in these regions and the innovation capacity of their neighbors. At the same time, the impact of innovation collaborative agglomeration in the same region on the innovation capacity of neighboring regions may be varied in different years. For instance, Beijing has negative local Moran values until 2014 in the knowledge innovation phase, while only 2015 had negative local Moran values between 2014 and 2017. In our analysis, we argue that innovation collaborative agglomeration can promote the regional innovation capacity through the mechanism of sharing, matching, and learning, but in the case of insufficient scale and quality of industry-universityresearch institution subject cohesion, improving the innovation collaborative agglomeration does not manifest in the improvement of regional innovation capacity. Additionally, there is a time lag in the improvement of regional innovation capacity. All of these reasons could lead to bivariate local Moran values with opposite signs in different years.

5.2. Results of Spatial Models. To compare and test the robustness of the parameter estimates of each variable, Classical Linear Regression (OLS), Spatial Autoregressive (SAR), Spatial Error Model (SEM), Spatial Durbin Model (SDM), and Spatial Durbin Error Model (SDEM) are built, respectively. Table 7 presents the empirical results for each model. 
TABLe 6: Results of bivariate local Moran values.

\begin{tabular}{|c|c|c|c|c|c|c|c|c|c|c|c|c|c|c|}
\hline \multirow[b]{2}{*}{ Year } & \multicolumn{7}{|c|}{$\mathrm{CO}$ and PA local Moran value } & \multicolumn{7}{|c|}{ CO and RNP local Moran value } \\
\hline & 2017 & 2016 & 2015 & 2014 & 2013 & 2012 & 2011 & 2017 & 2016 & 2015 & 2014 & 2013 & 2012 & 2011 \\
\hline Anhui & -0.36 & -0.26 & -0.34 & -0.39 & -0.39 & -0.47 & -0.43 & -0.55 & -0.36 & -0.39 & -0.38 & -0.31 & -0.29 & -0.20 \\
\hline Beijing & 0.52 & 0.04 & -0.34 & 0.04 & -0.32 & -0.64 & -0.62 & -1.32 & -0.37 & -0.12 & 0.58 & 0.96 & 0.73 & 0.30 \\
\hline Fujian & -2.27 & -2.06 & -1.96 & -2.13 & -2.05 & -1.82 & -1.77 & -0.97 & -1.06 & -0.93 & -1.01 & -1.08 & -0.91 & -0.84 \\
\hline Gansu & -0.38 & -0.29 & -0.41 & -0.45 & -0.46 & -0.50 & -0.53 & -0.82 & -0.78 & -0.69 & -0.66 & -0.67 & -0.74 & -0.80 \\
\hline Guangdong & -1.17 & -0.81 & -0.64 & -0.34 & -0.03 & 0.18 & 0.01 & -0.82 & -0.75 & -0.66 & -0.52 & -0.73 & -0.54 & -0.46 \\
\hline Guangxi & 0.26 & 0.09 & 0.17 & 0.17 & 0.06 & 0.00 & 0.02 & 0.33 & 0.29 & 0.24 & 0.15 & 0.20 & 0.10 & 0.07 \\
\hline Guizhou & 0.00 & 0.02 & 0.08 & 0.10 & 0.03 & 0.03 & 0.01 & 0.00 & 0.04 & 0.08 & 0.08 & 0.03 & 0.04 & 0.09 \\
\hline Hainan & 1.53 & 0.61 & 0.22 & 0.20 & 0.14 & 0.08 & 0.49 & 0.53 & 0.46 & 0.13 & 0.09 & 0.11 & 0.03 & 0.31 \\
\hline Hebei & 0.14 & 0.19 & 0.20 & 0.13 & 0.12 & 0.09 & 0.11 & 0.06 & 0.03 & 0.01 & -0.04 & -0.10 & -0.05 & -0.02 \\
\hline Henan & 0.48 & 0.18 & 0.37 & 0.34 & 0.25 & 0.19 & 0.13 & -0.23 & -0.14 & -0.07 & -0.09 & -0.13 & -0.01 & 0.08 \\
\hline Heilongjiang & -0.65 & -0.41 & -0.51 & -0.44 & -0.31 & -0.22 & -0.10 & -0.09 & -0.14 & -0.30 & -0.34 & -0.42 & -0.11 & -0.03 \\
\hline Hubei & 0.00 & -0.06 & -0.01 & 0.00 & 0.00 & 0.00 & 0.00 & -0.11 & -0.07 & -0.02 & 0.01 & -0.01 & 0.01 & 0.00 \\
\hline Hunan & -0.35 & -0.36 & -0.26 & -0.13 & -0.07 & -0.04 & -0.04 & -0.67 & -0.62 & -0.43 & -0.24 & -0.21 & -0.22 & -0.20 \\
\hline Jilin & -0.86 & -0.88 & -0.87 & -0.90 & -0.58 & -0.40 & -0.55 & -0.08 & -0.24 & -0.37 & -0.44 & -0.50 & -0.12 & -0.10 \\
\hline Jiangsu & -1.10 & -1.08 & -1.26 & -1.65 & -1.98 & -2.43 & -2.40 & -1.51 & -1.51 & -1.47 & -1.68 & -1.70 & -1.95 & -1.69 \\
\hline Jiangxi & -0.37 & -0.09 & -0.03 & 0.07 & -0.03 & 0.07 & 0.02 & -0.30 & -0.08 & -0.03 & 0.05 & -0.03 & 0.05 & 0.01 \\
\hline Liaoning & -0.41 & -0.46 & -0.40 & -0.26 & -0.20 & -0.21 & -0.17 & 0.05 & -0.02 & -0.06 & -0.04 & -0.07 & 0.03 & 0.02 \\
\hline Inner Mongolia & 0.22 & 0.46 & 0.52 & 0.38 & 0.21 & 0.05 & -0.01 & 0.11 & 0.34 & 0.32 & 0.25 & 0.17 & 0.03 & -0.01 \\
\hline Ningxia & 0.23 & 0.10 & 0.31 & 0.28 & 0.22 & 0.18 & 0.43 & 0.25 & 0.18 & 0.26 & 0.27 & 0.18 & 0.16 & 0.40 \\
\hline Qinghai & 0.00 & -0.07 & 0.06 & -0.13 & -0.11 & -0.15 & -0.18 & -0.65 & -0.58 & -0.95 & -0.41 & -0.46 & -0.48 & -0.51 \\
\hline Shandong & -0.08 & -0.13 & -0.33 & -0.47 & -0.89 & -1.35 & -1.46 & -0.94 & -0.84 & -0.90 & -0.89 & -0.99 & -1.03 & -0.80 \\
\hline Shanxi & 0.08 & 0.03 & 0.02 & 0.17 & 0.01 & -0.01 & 0.01 & 0.03 & 0.03 & 0.01 & 0.14 & 0.01 & -0.01 & 0.01 \\
\hline Shaanxi & -0.39 & -0.16 & -0.33 & -0.39 & -0.34 & -0.40 & -0.44 & -0.14 & -0.24 & -0.14 & -0.28 & -0.25 & -0.40 & -0.28 \\
\hline Shanghai & 0.38 & 0.28 & 0.38 & 0.71 & 0.64 & 0.79 & 0.68 & 0.37 & 0.31 & 0.35 & 0.60 & 0.46 & 0.53 & 0.42 \\
\hline Sichuan & -0.08 & 0.38 & 0.32 & 0.08 & 0.03 & -0.03 & -0.08 & -0.41 & -0.48 & -0.41 & -0.46 & -0.44 & -0.38 & -0.25 \\
\hline Tianjin & 0.00 & 0.00 & 0.04 & 0.00 & 0.03 & 0.06 & 0.03 & 0.01 & 0.03 & 0.01 & -0.04 & -0.08 & -0.07 & -0.01 \\
\hline Xinjiang & -0.18 & -0.46 & -0.28 & -0.82 & -0.77 & -0.89 & -0.52 & -1.32 & -1.28 & -1.06 & -1.18 & -1.32 & -1.39 & -0.89 \\
\hline Yunnan & -0.06 & -0.07 & 0.24 & 0.35 & 0.05 & -0.03 & -0.19 & -0.28 & -0.43 & -0.53 & -0.77 & -0.67 & -0.55 & -0.43 \\
\hline Zhejiang & -2.09 & -1.93 & -1.97 & -2.23 & -2.44 & -2.67 & -2.88 & -1.64 & -1.59 & -1.44 & -1.75 & -1.70 & -1.86 & -1.77 \\
\hline Chongqing & 0.07 & -0.19 & -0.20 & -0.16 & -0.02 & -0.01 & -0.02 & -0.10 & -0.12 & -0.18 & -0.14 & -0.01 & -0.01 & -0.06 \\
\hline
\end{tabular}

Considering the research question and the principle of Hausman's test and taking into account the existing literature $[54,55]$, the double fixed effect of time and space is more realistic. In Table 7, the LM_lag test (68.65) and Robust_LM_lag test (20.36) all pass the 5\% level of significance test for the OLS model at the knowledge innovation stage, which indicates a significant spatial effect between the variables. LR_lag test, Wald_lag test, LR_error test, and Wald_error test all pass the $1 \%$ significance level test in the SDM model and SDEM model. However, compared to the SDEM model, the $R^{2}$ in the SDM model is larger, so it is more appropriate to use the SDM model to analyze the impact of innovation collaborative agglomeration on regional innovation capacity at the knowledge innovation stage. The SDM model is also used in the outcome transformation stage.

Analysis of the SDM model for the knowledge innovation stage in Table 7 shows that the coefficients of $\mathrm{CO}$ and $\mathrm{CO}^{2}$ pass the $1 \%$ significance level test, indicating that the impact of innovation collaborative agglomeration on regional innovation capacity is significant. The $\mathrm{CO}$ coefficient is positive, while the $\mathrm{CO}^{2}$ coefficient is negative, indicating that, at the stage of knowledge innovation, with the increase of innovation collaborative agglomeration, regional innovation capacity first strengthens and then weakens, showing an inverted U-shaped relationship. This conclusion, which validates the hypothesis $H 1$, is in agreement with the findings of Liu et al. [14] and Lin and Tan [15]. The abovementioned existing studies use population density as a measure of agglomeration and usually attribute the congestion effect to the pollutant emissions and pressure on infrastructure that accompanies increased population density. However, the inverted U-shaped relationship between innovation collaborative agglomeration and regional innovation capacity is not entirely equivalent to the "Williamson" effect of agglomeration, as the lack of collaboration among innovation subjects is another important cause of the crowding effect. Connell et al. [56] found that industry agglomeration can stimulate knowledge sharing and collaborative innovation, and Resbeut and Gugler [8] also found that the more complementary closely related industries are, the higher the regional economic growth rate. The above study shows that the synergies effect among agglomerating subjects should not be ignored. Similarly, crowding effects are also supposed to be explained in terms of agglomeration and collaboration. Therefore, analyzing the reasons for the formation of an inverted U-shape from the perspective of URI innovation collaborative agglomeration, we think that the improvement of innovation collaborative agglomeration is the result of the combined effect of improving the level of collaboration and expanding the scale of innovation collaborative agglomeration. In the initial stage 


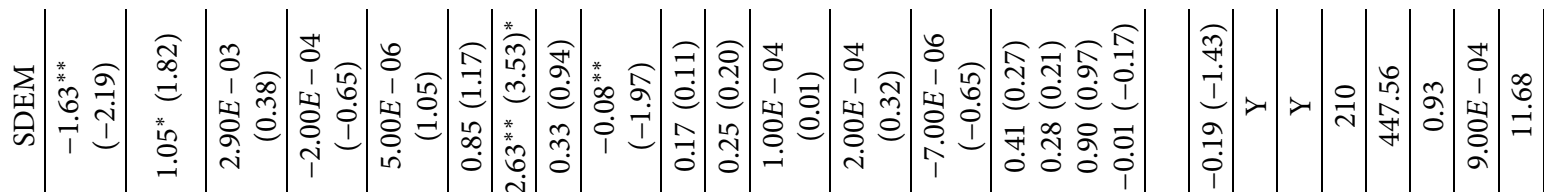

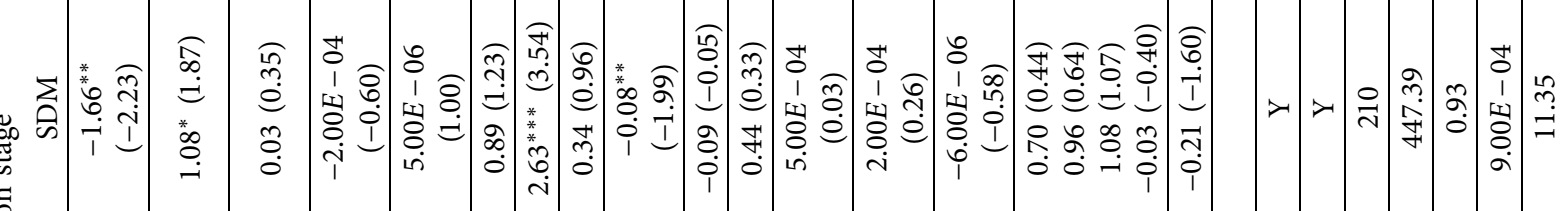

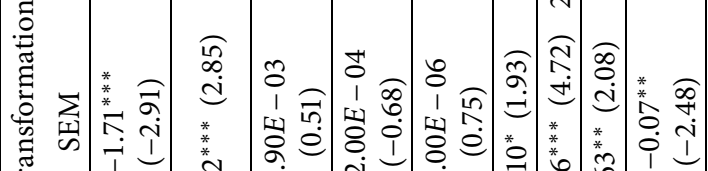

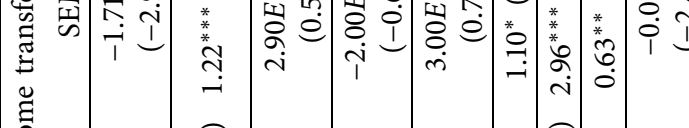

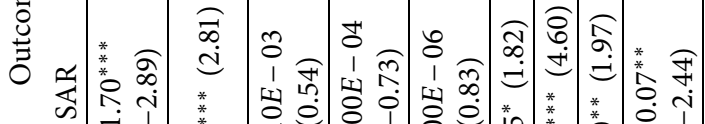

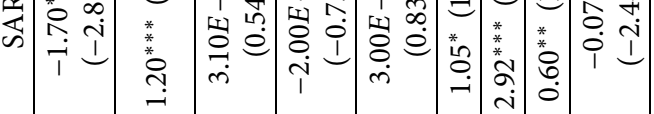

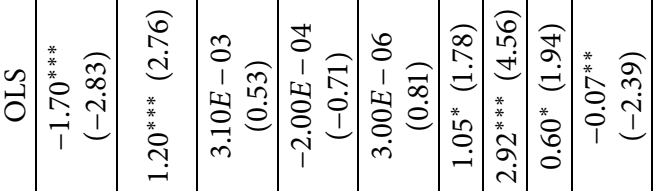

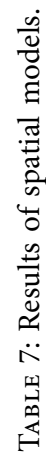

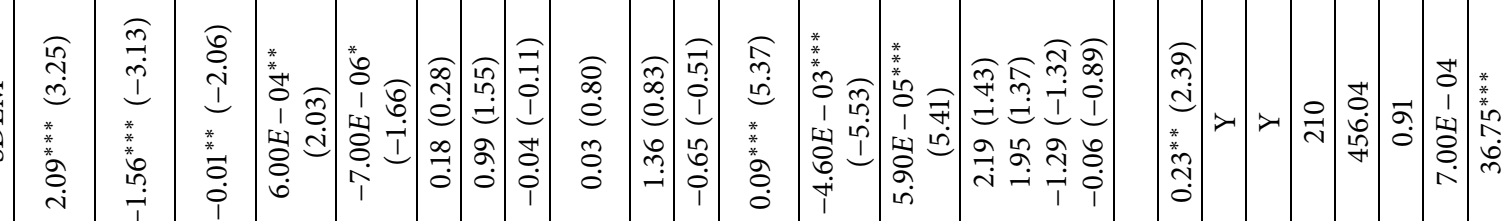

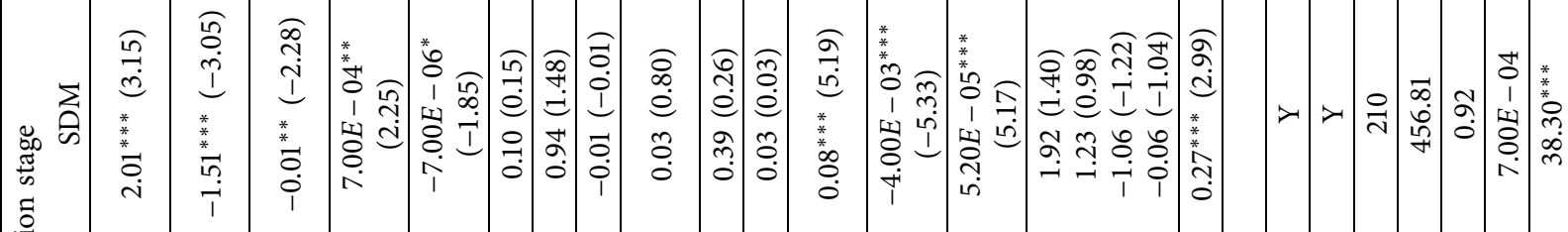

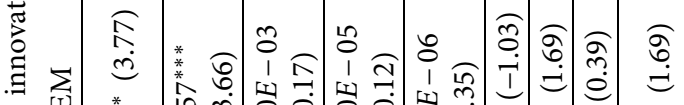

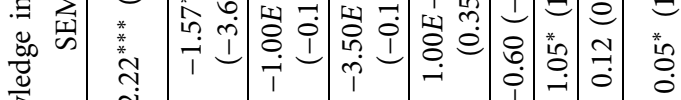

要

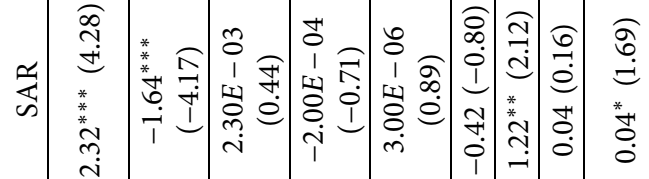

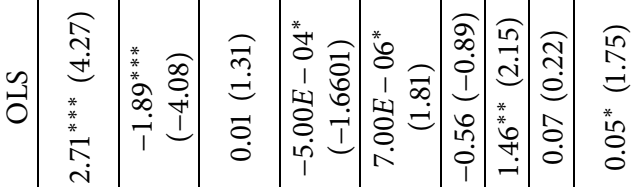

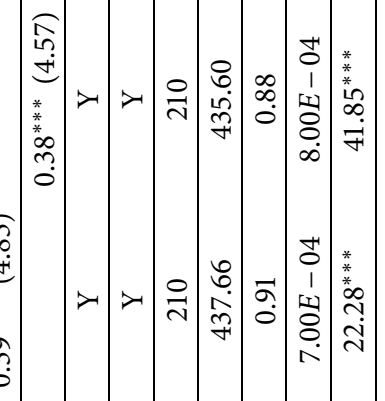

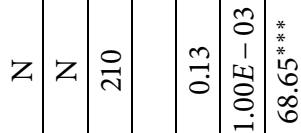

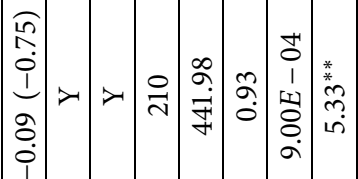

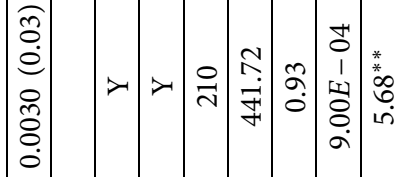

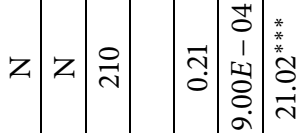




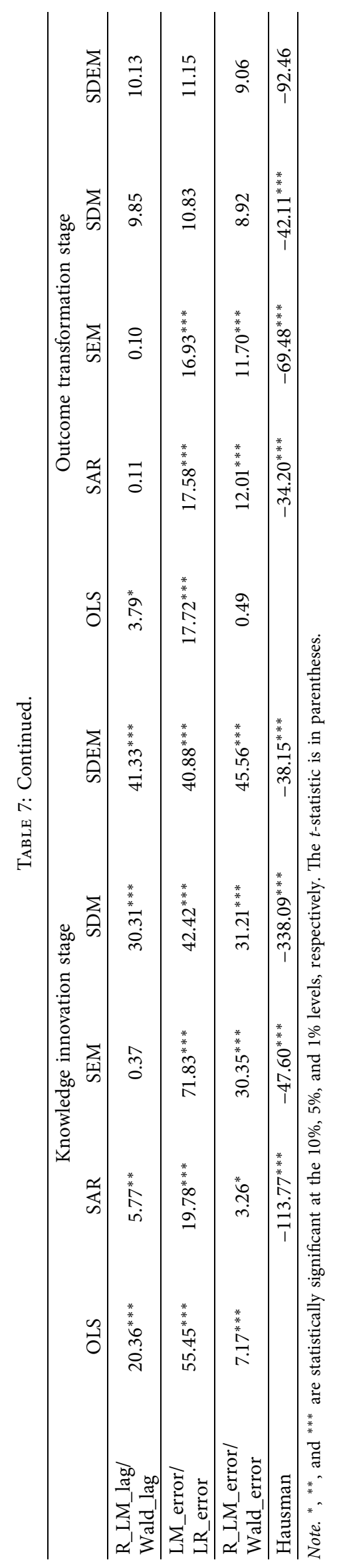


of knowledge innovation, with the continuous inflow of innovation resources, the scale of innovation subjects can be expanded and the regional innovation network is gradually improved, which is manifested in the innovation collaborative agglomeration that promotes the improvement of regional innovation capacity. However, with the continuous collaborative agglomeration of innovation subjects, the increasingly complex regional innovation network will increase the cost of cooperation among innovation subjects, and when the crowding effect is stronger than the innovation effect, regional innovation capacity will show a downward trend. The coefficients of human capital levels HUM, HUM ${ }^{2}$, and $\mathrm{HUM}^{3}$ in the SDM model of the knowledge innovation stage are significant at the 5\%,5\%, and $10 \%$ levels, respectively. The coefficient signs are negative, positive, and negative, showing that there is a significant inverted $\mathrm{N}$-shaped relationship between HUM and PA, thus validating the hypothesis H2. Innovation is dependent on the input of innovative people, and the level of human capital measures the amount of input of innovative people in the region. The inflow of innovative talents usually contributes to the enhancement of regional innovation capacity $[48,49]$, which is reflected in an inverted $\mathrm{N}$-shaped intermediate ascending segment. Yet, when the concentration of innovative talents reaches a critical value, the continued inflow of innovative talents intensifies the competition between innovative talents and resources, which is manifested by the negative correlation between the human capital and regional innovation capacity, specifically reflected in the second descending segment of the inverted $\mathrm{N}$ shape. The "ceiling" effect of labor pooling is also confirmed by Wang and Wang [57]. The first descending segment of the inverted $\mathrm{N}$ shape may be caused by two reasons. On the one hand, innovation activity depends not only on human capital inputs but also on inputs of other innovation factors such as physical capital. At the initial stage of knowledge innovation, although the inflow of innovative talents raises the level of human capital, innovation inputs are not fully matched. This has led to a unilateral overinvestment of human capital that is inconsistent with innovation output. On the other hand, there is usually a time lag effect on innovation activities, with innovation inputs in the current period often receiving innovation outputs in the next period. In the initial stage of knowledge innovation, the time lag in regional innovation capacity can also lead to a negative correlation.

The SDM model in the transformation stage shows that the CO coefficient is significant and HUM is not significant, indicating that at this stage, innovation collaborative agglomeration has a significant impact on the transformation of innovation results, while human capital has no significant impact on the outcome transformation. It is worth noting that here the coefficient signs for $\mathrm{CO}$ and $\mathrm{CO}^{2}$ are negative and positive, respectively, which is the opposite of the coefficient sign for the knowledge innovation stage. According to the analysis, at the stage of outcome transformation, the participation of university and research institution in cooperative agglomeration declines and the industry that obtained the patent right plays the main role. In other words, the production and sales links in the process of outcome transformation stage are completed by enterprises, which thus reduce the crowding effect brought about by the innovation collaborative agglomeration and makes a U-shaped relationship exist between innovation collaborative agglomeration and innovation achievement transformation. At the same time, after obtaining patent licenses, the demand for innovators by companies engaged in the production and sales decreases, and the contribution of innovators to production and sales is also greatly reduced. Therefore the coefficient on human capital at the outcome transformation stage fails the $10 \%$ level significance test.

The spatial autoregressive coefficients reflect the spatial effects of local and neighboring regions on regional innovation capacity. The spatial autoregressive coefficient of the knowledge innovation stage is 0.27 (2.99) and is significant at the $1 \%$ level. The result demonstrates that the local and neighboring regions of China have significantly promoted each other's innovation capacity in recent years. The dynamic flow of innovation factors among regions improves the scale of regional innovation factors, optimizes the allocation efficiency of innovation factors, and promotes knowledge spillovers among regions, thus helping to enhance the level of regional innovation [40]. At the same time, competition for innovation resources can easily lead to mutual suppression of the innovative knowledge output between neighboring regions, while close cooperation of innovative talents and spillover effects of innovative knowledge can weaken the suppression between regions. The spatial effect depends on the relative strength of the two effects, and a significant spatial autoregressive coefficient indicates that the current national knowledge spillover effect is significantly stronger than the suppression effect. The spatial autoregressive coefficient at the outcome transformation stage is $-0.21(-1.60)$ and does not pass the $10 \%$ level significance test. This result suggests that local and neighboring regions inhibit each other's ability to convert innovation outcomes at the innovation outcome stage, but this inhibition is not significant. The possible reason for this is that there is a competition between neighboring regions in the production and marketing activities based on patents, and the competition, in turn, raises the threshold for the transformation of innovations, thus affecting the ability to transform innovations, which is manifested in the mutual inhibition of the ability to transform innovations among neighboring regions.

\subsection{Analysis of Subregional Regression Results.} Considering the differences in development among regions, it is necessary to examine by subregion the impact of innovation collaborative agglomeration on regional innovation capacity. All the provinces in the study sample are divided into three main regions, east, middle, and west, according to geographical regions. The eastern region includes Beijing, Tianjin, Hebei, Shanghai, Suzhou, Zhejiang, Fujian, Shandong, Guangdong, Liaoning, and Hainan; the middle region includes Shanxi, Anhui, Jiangxi, Henan, Hubei, Hunan, Inner Mongolia, Jilin, and Heilongjiang; and 


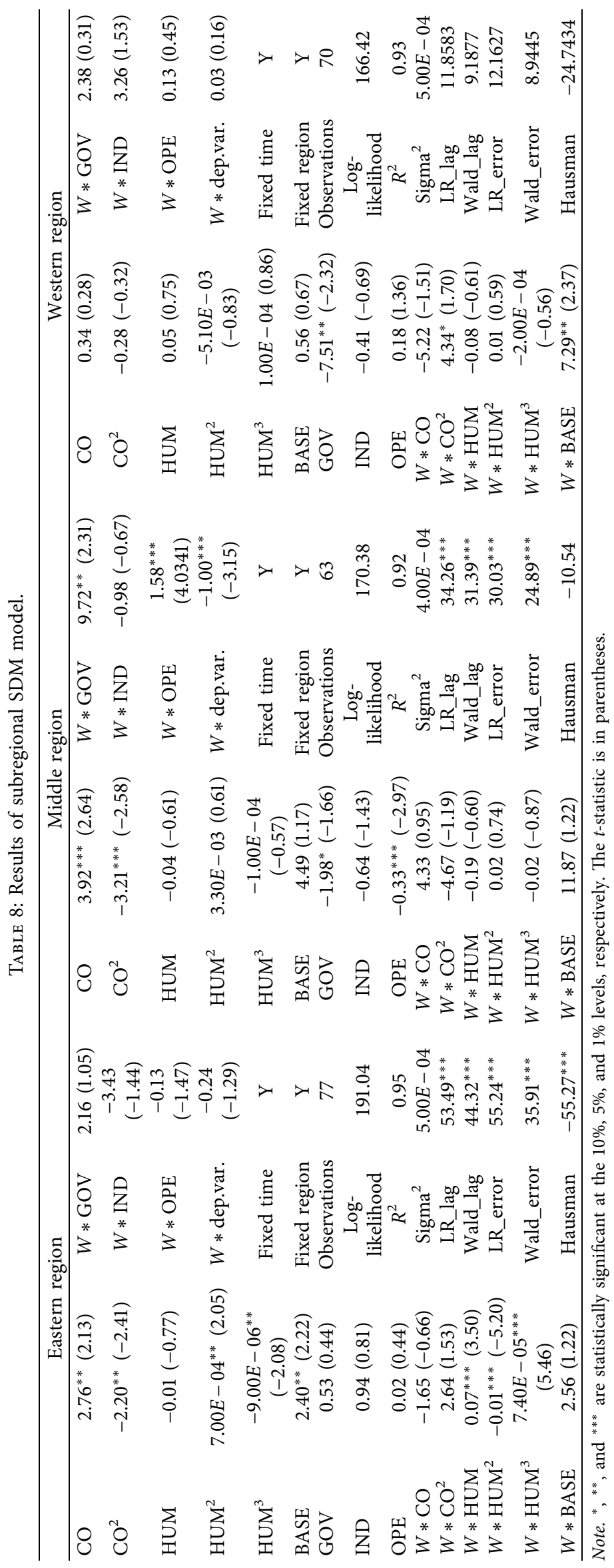


TABLE 9: Results of robustness test.

\begin{tabular}{|c|c|c|c|c|c|c|c|c|}
\hline & $\begin{array}{l}(1) \\
\mathrm{PA}\end{array}$ & $\begin{array}{c}(2) \\
\text { RNP }\end{array}$ & $\begin{array}{l}(3) \\
\text { PA }\end{array}$ & $\begin{array}{c}(4) \\
\text { RNP }\end{array}$ & $\begin{array}{l}(5) \\
\text { PA }\end{array}$ & $\begin{array}{c}(6) \\
\text { RNP }\end{array}$ & $\begin{array}{l}\text { (7) } \\
\text { PA }\end{array}$ & $\begin{array}{c}(8) \\
\text { RNP }\end{array}$ \\
\hline $\mathrm{CO}$ & $1.95^{* * *}(2.91)$ & $\begin{array}{l}-1.50^{* *} \\
(-2.02)\end{array}$ & $4.39^{* * *}(3.90)$ & $\begin{array}{c}-4.26^{* * *} \\
(-3.28)\end{array}$ & $\begin{array}{c}6.95^{* * *} \\
(5.94)\end{array}$ & $\begin{array}{l}-2.21^{*} \\
(-1.95) \\
\end{array}$ & $1.89^{* * *}(2.84)$ & $\begin{array}{c}-2.21^{* * *} \\
(-3.14)\end{array}$ \\
\hline $\mathrm{CO}^{2}$ & $\begin{array}{c}-1.46^{* * *} \\
(-2.82) \\
\end{array}$ & $1.02^{*}(1.77)$ & $\begin{array}{c}-2.91^{* * *} \\
(-3.51)\end{array}$ & $\begin{array}{c}3.34^{* * *} \\
(3.49) \\
\end{array}$ & $\begin{array}{c}-4.87^{* * *} \\
(-5.62)\end{array}$ & $\begin{array}{l}1.76^{* *} \\
(2.11) \\
\end{array}$ & $\begin{array}{c}-1.39^{* * *} \\
(-2.72)\end{array}$ & $\begin{array}{c}1.65^{* * *} \\
(3.05) \\
\end{array}$ \\
\hline HUM & $-0.01^{* *}(-2.07)$ & $\begin{array}{c}8.00 E-04 \\
(0.10)\end{array}$ & $-0.01^{*}(-1.90)$ & $\begin{array}{c}-1.60 E-03 \\
(-0.22)\end{array}$ & $\begin{array}{c}-37.77^{*} \\
(-1.79)\end{array}$ & $\begin{array}{c}-2.07 \\
(-0.10) \\
\end{array}$ & $\begin{array}{c}-0.02^{* * *} \\
(-3.02)\end{array}$ & $\begin{array}{c}-1.10 E-03 \\
(-0.14)\end{array}$ \\
\hline $\mathrm{HUM}^{2}$ & $\begin{array}{c}7.00 E-04^{* *} \\
(1.9602)\end{array}$ & $\begin{array}{c}-1.00 E-04 \\
(-0.28)\end{array}$ & $\begin{array}{c}6.00 E-04^{*} \\
(1.87) \\
\end{array}$ & $\begin{array}{c}1.00 E-04 \\
(0.18) \\
\end{array}$ & $5.15^{*}(1.87)$ & $0.18(0.07)$ & $\begin{array}{c}1.10 E-03^{* * *} \\
(3.08)\end{array}$ & $\begin{array}{c}-1.00 E-04 \\
(-0.25) \\
\end{array}$ \\
\hline $\mathrm{HUM}^{3}$ & $\begin{array}{c}-7.00 E-06 \\
(-1.59)\end{array}$ & $\begin{array}{c}3.00 E-06 \\
(0.67)\end{array}$ & $\begin{array}{c}-6.00 E-06 \\
(-1.51)\end{array}$ & $\begin{array}{c}-1.00 E-06 \\
(-0.02)\end{array}$ & $\begin{array}{l}-0.23^{*} \\
(-1.94)\end{array}$ & $\begin{array}{c}-3.70 E-03 \\
(-0.03)\end{array}$ & $\begin{array}{c}-1.20 E-05^{* * *} \\
(-2.71) \\
\end{array}$ & $\begin{array}{c}4.00 E-06 \\
(0.77)\end{array}$ \\
\hline BASE & $-0.24(-0.38)$ & $1.03(1.45)$ & $0.12(0.20)$ & $0.91(1.28)$ & $-0.90(-1.63)$ & $1.01^{*}(1.89)$ & $0.26(0.40)$ & $0.35(0.50)$ \\
\hline GOV & $1.16^{*}(1.72)$ & $\begin{array}{c}2.40^{* * * *} \\
(3.21) \\
\end{array}$ & $0.97(1.57)$ & $\begin{array}{c}2.76^{* * * *} \\
(3.90) \\
\end{array}$ & $\begin{array}{c}1.82^{* * *} \\
(2.62)\end{array}$ & $\begin{array}{c}3.12^{* * *} \\
(4.68) \\
\end{array}$ & $0.98(1.47)$ & $\begin{array}{c}2.90^{* * *} \\
(4.12) \\
\end{array}$ \\
\hline IND & $0.07(0.22)$ & $0.44(1.26)$ & $0.18(0.61)$ & $0.66^{*}(1.89)$ & $0.88^{* *}(2.24)$ & $\begin{array}{c}1.08^{* * *} \\
(2.86) \\
\end{array}$ & $0.52(1.50)$ & $0.58(1.58)$ \\
\hline OPE & $0.04(1.23)$ & $\begin{array}{c}-0.06 \\
(-1.47) \\
\end{array}$ & $0.04(1.46)$ & $\begin{array}{l}-0.06^{*} \\
(-1.68)\end{array}$ & $0.05^{* *}(1.98)$ & $\begin{array}{l}-0.05^{* *} \\
(-2.04)\end{array}$ & $0.04(1.11)$ & $\begin{array}{c}-0.05 \\
(-1.42) \\
\end{array}$ \\
\hline$W * \mathrm{CO}$ & $2.02(1.30)$ & $\begin{array}{l}-1.00 \\
(-0.59) \\
\end{array}$ & $0.77(0.31)$ & $\begin{array}{c}-2.13 \\
(-0.77) \\
\end{array}$ & $10.30(1.16)$ & $\begin{array}{c}16.65^{*} \\
(1.95) \\
\end{array}$ & $-1.09(-0.73)$ & $\begin{array}{c}-0.07 \\
(-0.05)\end{array}$ \\
\hline$W * \mathrm{CO}^{2}$ & $-1.11(-0.94)$ & $0.93(0.72)$ & $-0.21(-0.12)$ & $1.52(0.75)$ & $-9.44(-1.52)$ & $\begin{array}{c}-11.81^{* *} \\
(-1.98)\end{array}$ & $1.18(1.02)$ & $0.06(0.05)$ \\
\hline$W * \mathrm{HUM}$ & $0.09^{* * *}(5.03)$ & $\begin{array}{c}3.80 E-03 \\
(0.20) \\
\end{array}$ & $0.07^{* * *}(4.76)$ & $0.01(0.82)$ & $\begin{array}{l}-41.54 \\
(-0.13) \\
\end{array}$ & $\begin{array}{c}-147.62 \\
(-0.48) \\
\end{array}$ & $0.10^{* * *}(5.66)$ & $\begin{array}{c}-2.30 E-03 \\
(-0.13) \\
\end{array}$ \\
\hline$W * \mathrm{HUM}^{2}$ & $\begin{array}{c}-4.30 E-03^{* * *} \\
(-4.9614) \\
\end{array}$ & $\begin{array}{c}-3.80 E-05 \\
(-0.04)\end{array}$ & $\begin{array}{c}-3.90 E-03^{* * *} \\
(-5.07)\end{array}$ & $\begin{array}{c}-1.00 E-04 \\
(-0.61)\end{array}$ & $7.28(0.18)$ & $16.48(0.42)$ & $\begin{array}{c}-4.90 E-03^{* * *} \\
(-5.63)\end{array}$ & $\begin{array}{c}3.00 E-04 \\
(0.41)\end{array}$ \\
\hline$W * \mathrm{HUM}^{3}$ & $\begin{array}{c}1.00 E-04^{* * *} \\
(4.77) \\
\end{array}$ & $\begin{array}{c}-3.00 E-06 \\
(-0.27)\end{array}$ & $\begin{array}{c}1.00 E-04^{* * *} \\
(5.16) \\
\end{array}$ & $\begin{array}{c}2.00 E-06 \\
(0.17)\end{array}$ & $-0.40(-0.23)$ & $\begin{array}{c}-0.60 \\
(-0.36)\end{array}$ & $\begin{array}{c}6.10 E-05^{* * *} \\
(5.48) \\
\end{array}$ & $\begin{array}{c}-1.00 E-05 \\
(-0.88) \\
\end{array}$ \\
\hline$W * \mathrm{BASE}$ & $1.91(1.37)$ & $0.01(0.01)$ & $2.17^{*}(1.65)$ & $1.25(0.83)$ & $-4.35(-0.97)$ & $7.25^{*}(1.66)$ & $1.91(1.36)$ & $1.54(1.03)$ \\
\hline$W * \mathrm{GOV}$ & $1.21(0.85)$ & $1.31(0.80)$ & $1.22(1.01)$ & $1.21(0.85)$ & $\begin{array}{c}-0.01 \\
(-2.70 E-03)\end{array}$ & $6.11(1.36)$ & $0.22(0.17)$ & $0.22(0.15)$ \\
\hline$W *$ IND & $-0.85(-1.06)$ & $0.90(1.01)$ & $0.35(0.37)$ & $\begin{array}{c}-0.81 \\
(-0.75)\end{array}$ & $6.50^{*}(1.66)$ & $7.33^{*}(1.94)$ & $-0.93(-0.93)$ & $0.39(0.36)$ \\
\hline$W * \mathrm{OPE}$ & $-0.08(-1.14)$ & $\begin{array}{c}-0.07 \\
(-0.93) \\
\end{array}$ & $-0.12^{* *}(-2.39)$ & $\begin{array}{c}-2.00 E-03 \\
(-0.03)\end{array}$ & $-0.20(-0.70)$ & $0.07(0.25)$ & $-0.12^{* *}(-2.06)$ & $\begin{array}{c}-5.80 E-03 \\
(-0.10) \\
\end{array}$ \\
\hline$W *$ dep.var. & $0.22^{* *}(2.19)$ & $\begin{array}{c}-0.10 \\
(-0.81)\end{array}$ & $0.25^{* * *}(2.66)$ & $\begin{array}{c}-0.19 \\
(-1.41) \\
\end{array}$ & $\begin{array}{c}2.00 E-03 \\
(0.01)\end{array}$ & $\begin{array}{c}-0.87^{* * *} \\
(-3.40)\end{array}$ & $0.27^{* * *}(2.70)$ & $\begin{array}{c}-0.12 \\
(-0.87) \\
\end{array}$ \\
\hline Fixed time & $\mathrm{Y}$ & $\mathrm{Y}$ & $\mathrm{Y}$ & $\mathrm{Y}$ & $\mathrm{Y}$ & $\mathrm{Y}$ & $\mathrm{Y}$ & $\mathrm{Y}$ \\
\hline Fixed region & $\mathrm{Y}$ & $\mathrm{Y}$ & $\mathrm{Y}$ & $\mathrm{Y}$ & $\mathrm{Y}$ & $\mathrm{Y}$ & $\mathrm{Y}$ & $\mathrm{Y}$ \\
\hline Observations & 210 & 210 & 210 & 210 & 210 & 210 & 180 & 180 \\
\hline $\begin{array}{l}\text { Log- } \\
\text { likelihood }\end{array}$ & 453.05 & 446.90 & 463.07 & 453.82 & 451.61 & 452.85 & 395.87 & 401.82 \\
\hline$R^{2}$ & 0.92 & 0.93 & 0.93 & 0.93 & 0.91 & 0.94 & 0.92 & 0.94 \\
\hline Sigma $^{2}$ & $7.00 E-04$ & $9.00 E-04$ & $6.00 E-04$ & $8.00 E-04$ & $8.00 E-04$ & $7.00 E-04$ & $6.00 E-04$ & $7.00 E-04$ \\
\hline LR_lag & $33.02^{* * *}$ & 10.33 & $35.86^{* * *}$ & $14.84^{*}$ & $21.94^{* * *}$ & 11.29 & $38.67^{* * *}$ & $16.99^{* *}$ \\
\hline Wald_lag & $27.53^{* * *}$ & 7.83 & $28.77^{* * *}$ & 12.15 & $17.85^{* *}$ & 14.63 & $31.62^{* * *}$ & 13.74 \\
\hline LR_error & $36.17^{* * *}$ & 10.06 & $39.69^{* * *}$ & 14.22 & $21.00^{* *}$ & 7.61 & $38.80^{* * *}$ & $17.47^{* *}$ \\
\hline Wald_error & $28.61^{* * *}$ & 8.01 & $29.94^{* * *}$ & 11.25 & $18.27^{* *}$ & 12.06 & $28.60^{* * *}$ & 12.83 \\
\hline Hausman & $-47.66^{* * *}$ & -16.92 & $-74.93^{* * *}$ & -8.14 & $-62.07^{* * *}$ & $-60.87^{* * *}$ & $-60.93^{* * *}$ & $-37.66^{* * *}$ \\
\hline
\end{tabular}

Note. ${ }^{*},{ }^{* *}$, and ${ }^{* * *}$ are statistically significant at the $10 \%, 5 \%$, and $1 \%$ levels, respectively. The $t$-statistic is in parentheses. 
the western region includes Guangxi, Chongqing, Sichuan, Guizhou, Yunnan, Shaanxi, Gansu, Qinghai, Ningxia, and Xinjiang. The SDM model is built by region to investigate the impact at the knowledge innovation stage. The regression results are shown in Table 8.

The results of the subregional SDM model show that there is a significant nonlinear effect of CO and HUM on PA at the stage of knowledge innovation in the eastern region. There is an inverted U-shaped relationship between $\mathrm{CO}$ and PA that promotes and then inhibits, and HUM and PA show an inverted $\mathrm{N}$-shaped relationship that inhibits and then promotes and then inhibits, which is consistent with the empirical results obtained from the whole national sample data, whereas there is a significant inverted U-shaped effect of $\mathrm{CO}$ on PA in the middle region, and the effect of HUM on PA obeys the inverted $\mathrm{N}$-shaped relationship but its effect is not significant. Meanwhile, the effects of CO and HUM on PA in the western region obey the inverted U-shaped and $\mathrm{N}$-shaped relationships, respectively, and none of the coefficients pass the $10 \%$ level significance test. This result demonstrates that the impact of innovation collaborative agglomeration at the knowledge innovation stage in the middle, east, and west on regional innovation capacity is in the same direction but the significance of the impact differs, and the possible reason for this difference is the disparity in the collaborative agglomeration scale of IUR among regions. Innovation collaborative agglomeration encompasses both the quality and the scale of innovation collaborative agglomeration [32]. The scale of innovation collaborative agglomeration is large in the middle and eastern regions of China, and the impact of innovation collaborative agglomeration on regional innovation capacity is very significant. However, the lack of innovation resources in the western region has led to a low scale of innovation synergy clustering. Thus, the impact of innovation collaborative agglomeration on regional innovation capacity, although obeying an inverted $\mathrm{U}$-shaped relationship, is not yet evident, subject to the influence of the small scale of innovation collaborative agglomeration. Furthermore, the spatial autoregressive coefficients for both the middle and eastern regions are negative, indicating that the local and neighboring regions in the middle and eastern regions inhibit each others' innovation capacity, and the inhibitory effect is more pronounced in the middle region. Competition for limited innovation resources may be the main reason for the mutual suppression of innovation capacity among regions. In the middle and eastern regions, where economic growth is faster, the strong demand for innovative resources has exacerbated the disincentives among regions. The positive spatial autoregressive coefficients in the west reveal that local and neighboring regions mutually reinforce each other's innovation capacity. This is due to the overall low level of innovation activity in the west, where the lack of innovation resources not only limits competition but also provides an incentive to make the best use of limited innovation resources among regions.

\section{Robustness Test}

To further examine the robustness of the abovementioned empirical results of the SDM model, the following types of robustness tests are conducted separately in the study. First, the value of an attribute is usually relevant for an adjacent region, so the original spatial weight matrix is considered to be replaced by a geographic neighborhood matrix, and the results of this robustness test are shown in column (1) and column (2) of Table 9. Second, consider replacing the core explanatory variable $\mathrm{CO}$. $\mathrm{CO}$ indicator involves full-time equivalent data for $\mathrm{R} \& \mathrm{D}$ personnel, while $\mathrm{R} \& \mathrm{D}$ inputs from previous periods tend to affect current period outputs [58]. Therefore, the study uses the perpetual inventory method (15\% depreciation rate) to account for the inventory data of full-time equivalent of R\&D personnel [59], and then use this stock data to calculate the regional innovation collaborative agglomeration. The results of this robustness test are shown in Table 9, column (3) and column (4). Third, the simultaneous replacement of the spatial weight matrix and the $\mathrm{CO}$ and HUM indicators is considered, where the $\mathrm{CO}$ indicator is recalculated using the above stock data and the HUM indicator is measured by the commonly used logarithm of the number of students enrolled in tertiary education per 100,000 population. The basic form of the new economic distance spatial weight matrix $W^{\prime}$ is as follows:

$$
W^{\prime}=W_{\mathrm{d}} * \operatorname{diag}\left(\frac{\bar{P}_{1}}{\bar{P}}, \frac{\bar{P}_{2}}{\bar{P}}, \ldots, \frac{\bar{P}_{n}}{\bar{P}}\right)
$$

where $W_{\mathrm{d}}$ is the classical inverse distance spatial weight matrix, $\bar{P}_{i}$ is the average value of the physical capital stock of a region during the study period, and $\bar{P}$ is the average value of the national physical capital stock over the examination period. The value of the regional physical capital stock is deflated by the nominal fixed asset investment according to the fixed asset investment price index [60]. The results of this robustness test are shown in Table 9, column (5) and column (6). Finally, considering that innovation activities take a certain period from input to output, it is usually assumed that there is a time lag of one year from innovation input to output. Table 9, column (7) and column (8), presents the results of the robustness test for $\mathrm{CO}$ lag one period.

From the results of the robustness test in Table 9, it can be seen that the CO quadratic coefficients for the knowledge innovation stage are negative and all pass the $1 \%$ level significance test, which indicates an inverted U-shaped relationship between $\mathrm{CO}$ and PA. The coefficients of $\mathrm{HUM}^{3}$ in columns (1) and (3), although not significant, are negative, indicating an inverted $\mathrm{N}$-shaped relationship between HUM and PA. These results are consistent with the previous empirical results. The $\mathrm{CO}$ quadratic coefficients are all positive and significant at the outcome transformation stage, indicating a $\mathrm{U}$-shaped relationship between $\mathrm{CO}$ and $\mathrm{RNP}$ at this stage. The finding is also consistent with the previous results. This demonstrates the robustness and reliability of the conclusions in this study. 


\section{Conclusions and Implications}

China's economy has shifted from the stage of high-speed growth to the stage of high-quality development, and an innovation-driven economy has become the key to maintaining stable growth in China today. As the main body of regional innovation, the IUR sectors play a major role in enhancing regional innovation capacity and promoting innovation-driven economic growth. So, how to improve the innovation collaborative agglomeration to promote regional innovation capacity has become an important practical issue that needs to be resolved. Focusing on this issue, the study first proposes the concept of innovation collaborative agglomeration from the theory of synergistic clustering and theoretically derives the mechanism of innovation collaborative agglomeration influences regional innovation capacity. On this basis, using panel data from 30 provinces in mainland China (excluding Tibet) from 2011 to 2017 to establish the spatial models provides a robust empirical test of the theoretical mechanism. The main conclusions of this study are as follows.

There is a significant spatial correlation between innovation collaborative agglomeration and regional innovation capacity. Specifically, there is a significant negative spatial correlation between the local innovation collaborative agglomeration and the innovation capacity of neighboring regions in most of China in recent years, both at the knowledge innovation stage and the outcome transformation stage. Theoretically, enhancing the local innovation collaborative agglomeration when innovation resources are limited means attracting innovation resources from neighboring regions into the local area, which objectively leads to the rise and fall of local and neighboring regions' innovation collaborative agglomeration scale. This leads to a negative correlation in the spatial distribution between the increase in local innovation collaborative agglomeration and the decrease in innovation capacity in neighboring areas.

At the knowledge innovation stage, both the innovation collaborative agglomeration and the human capital have a significant impact on regional innovation capacity. The impact of innovation collaborative agglomeration on regional innovation capacity obeys an inverted U-shaped relationship. The increase in innovation collaborative agglomeration at the initial stage of knowledge innovation promotes resource matching, information sharing, and mutual learning among regional innovation subjects, reduces the cost of innovation, and thus improves regional innovation capacity. As the innovation collaborative agglomeration increases, excessive innovation collaborative agglomeration leads to a crowding effect. When the collaborative agglomeration effect is weaker than the crowding effect, further innovation collaborative agglomeration has the opposite effect on the improvement of regional innovation capacity. The impact of human capital on regional innovative capacity obeys an inverted N-shaped relationship. Usually, the collaborative agglomeration of innovation talents helps improve regional innovation capacity, but in the initial stage, the mismatched input of innovation factors and the lagging output together lead to the negative correlation between the human capital and regional innovation capacity. Also, excessive human capital will lead to a stronger crowding effect than innovation effect, which makes human capital and regional innovation capacity once again negatively correlated. At the outcome transformation stage, the impact of innovation collaborative agglomeration on regional innovation capacity is significant and obeys a U-shaped relationship, while the human capital does not have a significant impact on regional innovation capacity. The possible reason is the dominance of firms at the outcome transformation stage, which reduces the crowding effect caused by excessive collaborative agglomeration and resulting in a U-shaped relationship between innovation collaborative agglomeration and regional innovation capacity. Moreover, the contribution of innovative talents to the production and sales at this stage is also greatly reduced, resulting in the failure of the coefficient on the human capital to pass the significance level test.

There are significant spatial differences in the impact of innovation collaborative agglomeration on regional innovation capacity. The impact of innovation collaborative agglomeration on regional innovation capacity in the middle and eastern regions significantly obeys an inverted U-shaped relationship, while such an inverted U-shaped relationship exists but is not evident in the west. Also, at present, local innovation collaborative agglomeration in the middle region has a stronger inhibitory effect on the innovation capacity of neighboring regions than in the east. This result indicates that the size of innovation collaborative agglomeration has a large impact on regional innovation capacity. On the one hand, due to the small size of innovation collaborative agglomeration in the western region, an inverted U-shaped relationship is present but not significant. On the other hand, the competition for limited innovation resources is the key factor that leads to the existence of an inverted U-shaped relationship in the middle region.

The above conclusions have important policy implications for improving China's regional innovation capacity and promoting coordinated regional development.

Enhance the innovation collaborative agglomeration of local IUR sectors and promote complementary innovation advantages in neighboring regions. Guiding the fusion and development of the local IUR sectors, optimizing the allocation of local resources, actively building a regional innovation network, and increasing the innovation collaborative agglomeration of local will help promote the enhancement of local innovation capacity. However, with limited innovation resources, local innovation collaborative agglomeration attracts an inflow of innovation resources to the detriment of innovation capacity in neighboring regions. Hence, it should also strengthen the docking of innovation policies among neighboring regions, actively carry out cooperation projects for IUR sectors, and give full play to the complementary role of regional advantages, to realize the joint improvement of the innovation capacity of neighboring regions.

Rationalize the innovation collaborative agglomeration to avoid crowding effects. There is a critical mass of innovation collaborative agglomeration for the improvement of 
regional innovation capacity, and excessive innovation collaborative agglomeration leads to crowding-out effects. Government support for innovative activities will help to alleviate crowding effects. For this reason, government departments should lead from the supply side and control from the demand side. In other words, the government should take the market as the main body to reasonably guide the inflow and allocation of innovation resources, optimize the layout of regional innovation industries, build a regional innovation synergistic agglomeration network, make up for the defects of market failure, and avoid the crowding effect brought about by the excessive agglomeration of innovation subjects.

Promote the inter-regional flow of innovative resources and the coordinated development of the national innovation economy. There are spatial differences in the impact of innovation collaborative agglomeration on regional innovation capacity, and the influence is significantly stronger in the middle and eastern regions than in the western region. Therefore, inter-regional exchanges and cooperation among IUR sectors should be strengthened. Rely on knowledge dissemination technology to strengthen the exchange of information and knowledge sharing among regions and rely on modern transportation technology to rationally arrange industries to expand the space for the development of the regional innovative economy. Promote the docking of interregional innovation collaborative agglomeration networks to further unleash the vitality of the innovative economy and narrow the gap of the innovation economy.

\section{Data Availability}

The data used to support the findings of the study are available from the corresponding author upon request.

\section{Conflicts of Interest}

The authors declare that there are no conflicts of interest regarding the publication of this paper.

\section{Acknowledgments}

This paper was supported by the National Natural Science Foundation (71573138); Jiangsu Social Science Foundation (16JD005); and Jiangsu Funded by the Provincial Soft Science Project (BR2019048).

\section{References}

[1] J. Wu, "Establishing the new normal of China's economy with deepening reforms," Exploration and Free Views, vol. 1, pp. 4-7, 2015.

[2] S. Lv and Z. Dai, "Theoretical implication and realization path of high-quality development in new era," Economic Review Journal, vol. 3, pp. 16-22, 2019.

[3] H. Etzkowitz, "Innovation in innovation: the triple helix of university-industry-government relations," Social Science Information, vol. 42, no. 3, pp. 293-337, 2003.

[4] H. D. Evers, S. Gerke, and T. Menkhoff, "Knowledge clusters and knowledge hubs: designing epistemic landscapes for development," Journal of Knowledge Management, vol. 14, no. 5, pp. 678-689, 2010.

[5] J. Zhang, Y. Hou, P. Liu, J. He, and X. Zhuo, "Goal requirements and strategic paths for high-quality development," Management World, vol. 35, no. 7, pp. 1-7, 2019.

[6] X. Cai and J. Zhao, "Research on the efficiency and influencing factors of university-industry-government synergistic innovation," Soft Science, vol. 33, no. 2, pp. 56-60, 2019.

[7] E. Romanelli and O. M. Khessina, "Regional industrial identity: cluster configurations and economic development," Organization Science, vol. 16, no. 4, pp. 344-358, 2005.

[8] M. Resbeut and P. Gugler, "Impact of clusters on regional economic performance," Competitiveness Review, vol. 26, no. 2, pp. 188-209, 2016.

[9] M. Resbeut, P. Gugler, and D. Charoen, "Spatial agglomeration and specialization in emerging markets," Competitiveness Review, vol. 29, no. 3, pp. 236-252, 2019.

[10] K. Futagami and Y. Ohkusa, "The quality ladder and product variety: larger economies may not grow faster," The Japanese Economic Review, vol. 54, no. 3, pp. 336-351, 2003.

[11] F. Zhang and G. Huo, "An evaluation model of innovative efficiency on national research institutes," Scientific Research Management, vol. 2, pp. 35-42, 2007.

[12] W. Pan and Q. Liu, "China's manufacturing industry agglomeration and regional economic growth-research based on the data of Chinese industrial enterprises," Journal of Tsinghua University (Philosophy and Social Sciences), vol. 27, no. 1, pp. 137-147, 2012.

[13] Y. Xu, H. Peng, and X. Liu, "Williamson hypothesis: spatial agglomeration and growth of regional economy-an empirical analysis based on threshold regression using China's regional data," Economic Theory and Business Management, vol. 4, pp. 95-102, 2011.

[14] X. Liu, J. Shao, and Y. Xue, "Agglomeration and region economic growth: an empirical review based on panel data of Chinese prefecture cities," Nankai Economic Studies, vol. 3, pp. 52-64, 2012.

[15] B. Lin and R. Tan, "Economic agglomeration and green economy efficiency in China," Economic Research Journal, vol. 54, no. 2, pp. 119-132, 2019.

[16] M. Yu and F. Zhu, "Study on the mechanism of innovation clustering capacity impact on innovation clustering performance," Studies in Science of Science, vol. 33, no. 6, pp. 924-933, 2015.

[17] W. M. Cohen, R. R. Nelson, and J. P. Walsh, "Links and impacts: the influence of public research on industrial R\&D," Management Science, vol. 48, no. 1, pp. 1-23, 2002.

[18] M. Buesa, J. Heijs, and T. Baumert, "The determinants of regional innovation in Europe: a combined factorial and regression knowledge production function approach," $R e$ search Policy, vol. 39, no. 6, pp. 722-735, 2010.

[19] W. Yu, X. Gu, and W. Xiong, "Research on knowledge division and knowledge synergy of industry-university-research institute collaboration," Studies in Science of Science, vol. 35, no. 5, pp. 737-745, 2017.

[20] Y. Hong, "On the innovation-driven economic development," Economist, vol. 1, pp. 5-11, 2013.

[21] J. Tong and F. Li, "A comparative study of the innovation cluster effect in the innovative city-a case of Shanghai and Nanjing," Science \& Technology Progress and Policy, vol. 32, no. 19, pp. 35-39, 2015.

[22] S. Ke, "Agglomeration, productivity, and spatial spillovers across Chinese cities," The Annals of Regional Science, vol. 45, no. 1, pp. 157-179, 2010. 
[23] Y. Ushifusa and A. Tomohara, "Productivity and labor density: agglomeration effects over time," Atlantic Economic Journal, vol. 41, no. 2, pp. 123-132, 2013.

[24] Y. Liu and B. Liu, "The influence and mechanism of co-agglomeration between producer services and manufactures to the manufacturing efficiency-empirical research based on the panel dada of China's urban agglomerations," Business Management Journal, vol. 38, no. 6, pp. 16-28, 2016.

[25] P. Jiao and X. Lin, "The effect of the synergistic agglomeration of producer service FDI and manufacturing FDI on manufacturing growth," Inquiry into Economic Issues, vol. 6, pp. 85-93, 2016.

[26] H. Zhang, A. Han, and Q. Yang, "Spatial effect analysis of synergetic agglomeration of manufacturing and producer services in China," The Journal of Quantitative \& Technical Economics, vol. 34, no. 2, pp. 3-20, 2017.

[27] Y. Feng and X. Wang, "A study on the impact of China's manufacturing industry and producer service industry coagglomeration on new urbanization," Inquiry into Economic Issues, vol. 11, pp. 66-76, 2018.

[28] X. Wu, "Research on threshold effect of industrial co-agglomeration's impact on total factor productivity-based on the empirical test of 246 cities in China," Economic Survey, vol. 36, no. 2, pp. 72-78, 2019.

[29] G. Ellison, E. L. Glaeser, and W. R. Kerr, "What causes industry agglomeration? evidence from coagglomeration patterns," American Economic Review, vol. 100, no. 3, pp. 1195-1213, 2010.

[30] G. Duranton and H. G. Overman, "Exploring the detailed location patterns of U.K. manufacturing industries using microgeographic data," Journal of Regional Science, vol. 48, no. 1, pp. 213-243, 2008.

[31] B. Stephen and B. Erik, "Agglomeration within an urban area," Journal of Urban Economics, vol. 91, pp. 13-25, 2016.

[32] G. Chen and J. Chen, "Industry association, spatial geography and secondary and tertiary industry clustering-experience from 212 cities in China," Management World, vol. 4, pp. 82-100, 2012.

[33] J. Chen, Y. Liu, and M. Zou, "The improvement of city productivity based on synergy and co-agglomeration of industries: under the background of integrated innovation and conversion of driving force of economic development in China," Journal of Zhejiang University (Humanities and Social Science), vol. 46, no. 3, pp. 150-163, 2016.

[34] L. Yang and Z. Sun, "The development of western new-type urbanization level evaluation based on entropy method," On Economic Problems, vol. 3, pp. 115-119, 2015.

[35] H. Zhang and A. Han, "Can the coupling between manufacturing and productive services enhance spatial coordination - a test based on data from 285 cities in China," Statistical Research, vol. 36, no. 1, pp. 39-50, 2019.

[36] A. Ciccone and R. Hall, "Productivity and the density of economic activity," The American Economic Review, vol. 86, no. 1, pp. 54-70, 1996.

[37] Y. Zhang and K. Li, "Research on the spatial dependence of Chinese province-level innovative output," Studies in Science of Science, vol. 3, pp. 659-665, 2008.

[38] J. Li, Q. Tan, and J. Bai, "Spatial econometric analysis of regional innovation production in China-an empirical study based on static and dynamic spatial panel models," Management World, vol. 7, pp. 43-55+65, 2010.

[39] Y. Yu and D. Liu, "Innovation essential factor cluster and the spatial spillover of technological innovation efficiency in
China," Science Research Management, vol. 34, no. 1, pp. 46-54, 2013.

[40] J. Bai and F. Jiang, "Synergy innovation, spatial correlation and regional innovation performance," Economic Research Journal, vol. 50, no. 7, pp. 174-187, 2015.

[41] J. P. Elhorst, "Matlab software for spatial panels," International Regional Science Review, vol. 37, no. 3, pp. 389-405, 2014.

[42] L. Anselin, "A test for spatial autocorrelation in seemingly unrelated regressions," Economics Letters, vol. 28, no. 4, pp. 335-341, 1988.

[43] J. Elhorst and S. Frerets, "Yardstick competition among local govets: French evidence using a two-regimes spatial panel data model," Journal of Regional Science, vol. 49, no. 2, pp. 931-951, 2009.

[44] G. Huang, J. Xu, and Y. Li, "Science-technology value chains and the linking models among multiple innovation entities," China Soft Science, vol. 6, pp. 67-75, 2006.

[45] W. Suo, J. Gao, and R. Chen, "Technology policy, strategy and innovation performance in Chinese aircraft and spacecraft manufacturing," Studies in Science of Science, vol. 33, no. 2, pp. 234-241, 2015.

[46] X. Xiong, Z. Guan, G. Yang, and H. Zheng, "Measuring S\&T efficiency and its decomposition using a two-stage DEA model with nested parallel structure," Chinese Journal of Management Science, vol. 27, no. 3, pp. 206-216, 2019.

[47] J. Bai and Y. Bian, "Factor market distortion and the efficiency losses of Chinese innovative production," Science Research Management, vol. 37, no. 1, pp. 77-83, 2016.

[48] J. Li, Q. Tan, and J. Bai, "Stochastic frontier analysis on the regional innovation efficiency of China," China Population, Resources and Environment, vol. 19, no. 6, pp. 142-147, 2009.

[49] Y. Wang, D. Sheng, B. Shi, and K. Li, "How does infrastructure affect export technological sophistication," Economic Research Journal, vol. 45, no. 7, pp. 103-115, 2010.

[50] Y. Pu and R. Gu, "How do labor wage distortions affect enterprise innovation," China Industrial Economics, vol. 7, pp. 137-154, 2019.

[51] H. Liu, "Research on regional R\&D efficiency and its influencing factors-empirical analysis based on stochastic frontier function," Studies in Science of Science, vol. 29, no. 4, pp. 548-556, 2011.

[52] G. Lin, Z. Long, and M. Wu, "A spatial investigation of $\sigma$-convergence in China," The Journal of Quantitative \& Technical Economics, vol. 4, pp. 14-21, 2006.

[53] K. Rusche, U. Kies, and A. Schulte, "Measuring spatial coagglomeration patterns by extending ESDA techniques," Jahrbuch für Regionalwissenschaft, vol. 31, no. 1, pp. 11-25, 2011.

[54] B. Zhang, Y. Zhan, and K. Zhou, "Agglomeration, diversity and regional economic growth: an empirical study from China's manufacturing industry," World Economic Papers, vol. 3, pp. 16-29, 2007.

[55] W. Li and H. Lv, "Interactions between shareholders' balance mechanism and level of listed companies' cash dividends," Chinese Journal of Management, vol. 1, pp. 84-90, 2009.

[56] J. Connell, A. Kriz, and M. Thorpe, "Industry clusters: an antidote for knowledge sharing and collaborative innovation?" Journal of Knowledge Management, vol. 18, no. 1, pp. 137-151, 2014.

[57] J. Wang and M. Wang, "Influence of spatial agglomeration of labor on economic growth in China," Research on Economics and Management, vol. 40, no. 3, pp. 86-106, 2019. 
[58] Y. Wu, "R\&D stock, knowledge function and productive efficiency," China Economic Quarterly, vol. 3, pp. 1129-1156, 2006.

[59] J. Bai, K. Jiang, and J. Li, "On the efficiency and total factor productivity growth of China's R\&D innovation," The Journal of Quantitative \& Technical Economics, vol. 26, no. 3, pp. 139-151, 2009.

[60] J. Zhang, G. Wu, and J. Zhang, “The estimation of China's provincial capital stock: 1952-2000," Economic Research Journal, vol. 39, no. 10, pp. 35-44, 2004. 